\title{
Aberrant Restoration of Spines and their Synapses in L-DOPA-Induced Dyskinesia: Involvement of Corticostriatal but Not Thalamostriatal Synapses
}

\author{
Yiyue Zhang, ${ }^{1,2}$ Gloria E. Meredith, ${ }^{1}$ Nasya Mendoza-Elias, ${ }^{1,2}$ David J. Rademacher, ${ }^{3}$ Kuei Y. Tseng, ${ }^{2}$ \\ and Kathy Steece-Collier ${ }^{3}$ \\ ${ }^{1}$ Department of Pharmaceutical Sciences, College of Pharmacy, and 2Department of Cellular and Molecular Pharmacology, Chicago Medical School, \\ Rosalind Franklin University of Medicine and Science, North Chicago, Illinois 60064, and ${ }^{3}$ Department of Translational Science and Molecular Medicine, \\ Michigan State University, Grand Rapids, Michigan 49503
}

We examined the structural plasticity of excitatory synapses from corticostriatal and thalamostriatal pathways and their postsynaptic targets in adult Sprague-Dawley rats to understand how these striatal circuits change in L-DOPA-induced dyskinesias (LIDs). We present here detailed electron and light microscopic analyses that provide new insight into the nature of the structural and synaptic remodeling of medium spiny neurons in response to LIDs. Numerous studies have implicated enhanced glutamate signaling and persistent long-term potentiation as central to the behavioral sensitization phenomenon of LIDs. Moreover, experience-dependent alterations in behavior are thought to involve structural modifications, specifically alterations in patterns of synaptic connectivity. Thus, we hypothesized that in the striatum of rats with LIDs, one of two major glutamatergic pathways would form new or altered contacts, especially onto the spines of medium spiny neuron (MSNs). Our data provide compelling evidence for a dramatic rewiring of the striatum of dyskinetic rats and that this rewiring involves corticostriatal but not thalamostriatal contacts onto MSNs. There is a dramatic increase in corticostriatal contacts onto spines and dendrites that appear to be directly linked to dyskinetic behaviors, since they were not seen in the striatum of animals that did not develop dyskinesia. There is also an aberrant increase in spines receiving more than one excitatory contact(i.e., multisynaptic spines) in the dyskinetic animals compared with the 6-hydroxydopamine-treated and control rats. Such alterations could substantially impair the ability of striatal neurons to gate cortically driven signals and contribute to the loss of bidirectional synaptic plasticity.

\section{Introduction}

The gold standard therapy for Parkinson's disease (PD) is L-3,4dihydroxyphenylalanine (L-DOPA). While initially effective, long-term therapy frequently results in abnormal involuntary movement (AIM) side-effects termed L-DOPA-induced dyskinesias (LIDs). LIDs have plagued patients and clinicians since the introduction of L-DOPA (Cotzias et al., 1969; Yahr et al., 1969). An abundant literature describes divergent neurotransmitters, receptors, and downstream signaling changes associated with LIDs (Aubert et al., 2005; St-Hilaire et al., 2005; Guigoni et al., 2007; Lee et al., 2008). Of particular interest has been the idea that increases in glutamate signaling, secondary to striatal dopamine

\footnotetext{
Received Jan. 21, 2013; revised May 7, 2013; accepted June 5, 2013.

Author contributions: Y.Z., G.E.M., and K.S.-C. designed research; Y.Z. and G.E.M. performed research; Y.Z., G.E.M., N.M.-E., D.J.R., and K.Y.T. analyzed data; Y.Z., G.E.M., K.Y.T., and K.S.-C. wrote the paper.

This work was supported by NIH Grants R01 NS04513 (to K.S.-C.) and P50 NS058830. The authors thank Figen Seiler and the Electron Microscopy Center, Nathan Levine, Jennifer Stancati, Courtney Chan, and Aditi Thakkar for their technical assistance.

The authors declare no competing financial interests.

Correspondence should be addressed to Dr. Gloria E. Meredith, Department of Pharmaceutical Science, Rosalind Franklin University of Medicine and Science, 3333 Green Bay Road, North Chicago, IL 60064. E-mail: gloria.meredith@rosalindfranklin.edu.

DOI:10.1523/JNEUROSCI.0288-13.2013

Copyright $\odot 2013$ the authors $\quad 0270-6474 / 13 / 3311655-13 \$ 15.00 / 0$
}

depletion, is central to the development of LIDs (Ahmed et al., 2011; Ghiglieri et al., 2012).

There is an extensive glutamatergic input to the striatum that arises primarily from cortex and thalamus. The main synaptic target of this input and that of nigral dopamine neurons is the striatal principle neuron, the medium spiny neuron (MSN). There are differential synaptic organizations and functional properties associated with these glutamatergic inputs (Lacey et al., 2005; Ding et al., 2008). Anatomically, corticostriatal afferents preferentially contact spines that stud MSNs, whereas thalamostriatal afferents synapse with both spines and dendritic shafts (Dubé et al., 1988; Xu et al., 1991; Lacey et al., 2005). In PD, the loss of nigrostriatal dopamine neurons results in the loss of dopaminergic synapses, MSN spine retraction, and the loss of glutamatergic synapses (Ingham et al., 1989, 1998; Day et al., 2006). Because of the interaction between striatal dopamine and glutamate, these morphological changes interfere with the bidirectional synaptic plasticity phenomena, long-term potentiation (LTP) and long-term depression (LTD).

These opposing processes are important for the storage and retrieval of motor learning programs and elimination of nonessential motor information (Graybiel, 1995; Picconi et al., 2012). In subjects with LIDs, this bidirectional plasticity is altered in the striatum. Specifically, in dyskinetic rats, LTP is unstable while LTD can no longer be reliably induced (Picconi et al., 2003). 
These data suggest that overactivity of excitatory projections to the striatum plays an important role in LIDs.

Long-term potentiation is associated with increases in synaptic proteins (i.e., synaptogenesis and expansion of the active zones of synapses; Geinisman et al., 1992, 1994, 2001; Geinisman, 2000). Interestingly, increases in proteins involved with synaptic and structural plasticity have been found in rats with LIDs (Konradi et al., 2004; Nash et al., 2005). Thus, the functional plasticity associated with LIDs may be linked to increases in excitatory synapses of corticostriatal or thalamostriatal pathways. In the current study, we compared the synaptic profiles of corticostriatal [vesicular glutamate transporter 1 (VGluT1)] and thalamostriatal (VGluT2) innervations in rats with LIDs. We also characterized morphological changes in MSNs that enable the neurons to adapt to these synaptic modifications. To unequivocally determine that synaptic changes were associated with LIDs per se, we controlled for the impact of L-DOPA in control rats (sham/L-DOPA) and parkinsonian rats that failed to develop dyskinesia [6-hydroxydopamine (6-OHDA)/L-DOPA].

\section{Materials and Methods}

\section{Animal treatments}

Adult, male, Sprague-Dawley rats (200-250 g at the time of surgery; Harlan) were housed two to a cage, and provided with food and water $a d$ libitum. Rats were maintained on a $12 \mathrm{~h}$ light/dark cycle. All studies were performed in accordance with the Institute for Laboratory Animal Research of the National Academy of Science Guide for the Care and Use of Laboratory Animals and were approved by the Institutional Animal Care and Use Committee at Rosalind Franklin University of Medicine and Science, where the ultrastructural studies were performed, and at Michigan State University, where Golgi-Cox studies were conducted. All efforts were made to minimize the number of animals used and their pain or discomfort.

Rats for the synaptic studies were anesthetized ( $3 \mathrm{ml} / \mathrm{kg}$, i.p.) with equithesin ( $1 \%$ ethanol, $44 \%$ propylene glycol, $1 \%$ pentobarbital sodium, $4 \%$ chloral hydrate, and $2 \%$ magnesium sulfate) and then secured in a stereotaxic frame. Each rat was given either a 6-OHDA ( $2 \mu \mathrm{l}$ of a 5 $\mathrm{mg} / \mathrm{ml} 6$-OHDA solution in saline with $0.2 \%$ ascorbic acid) or sham lesion. The toxin was delivered by Hamilton syringe into two sites unilaterally, as follows: medial forebrain bundle $(4.3 \mathrm{~mm}$ posterior to bregma, $1.2 \mathrm{~mm}$ lateral of the mid-sagittal suture, $7.5 \mathrm{~mm}$ ventral from the dura) and substantia nigra pars compacta ( $\mathrm{SNc} ; 4.8 \mathrm{~mm}$ posterior to bregma, $1.7 \mathrm{~mm}$ lateral, $7.5 \mathrm{~mm}$ ventral). Each sham lesion involved making a burr hole over the same two locations but without needle penetration or fluid injection. Four weeks after the lesion, each rat received an intraperitoneal injection of sterile saline, or L-DOPA and benserazide (12.5 mg/kg L-DOPA and $12.5 \mathrm{mg} / \mathrm{kg}$ benserazide in sterile saline) once daily (Monday through Friday) for 3 weeks (Fig. 1).

Rats were assigned to the following groups: (1) sham/saline (intact control plus vehicle, $n=6$ ); (2) sham/L-DOPA (intact plus L-DOPA, $n=$ 6); (3) 6-OHDA/saline (parkinsonian plus vehicle [L-DOPA naive] $n=$ 6); and (4) 6-OHDA/L-DOPA (parkinsonian plus L-DOPA, $n=17$ ). The last group was divided into three subgroups according to the severity of AIMs (severe, moderate, or mild; see below). The lesion was verified drug free with cylinder and vibrissae tests (Schallert, 2006), and the stereological quantification of tyrosine hydroxylase-immunopositive $\left(\mathrm{TH}^{+}\right)$cells in the postmortem SNc (Stereo Investigator, MBF Bioscience).

Motor analyses

Cylinder and vibrissae tests. The cylinder test analyzes contralateral forelimb akinesia. Each rat was placed in a clear Plexiglas cylinder sur- rounded by mirrors to allow the evaluation of forepaw movements. Each animal was videotaped for $4 \mathrm{~min}$ at the beginning of their dark cycle, a time during the light/dark cycle in which spontaneous locomotor activity is elevated. The videotapes were evaluated for the number of weightbearing contacts made on the cylinder wall with the left, right, or both forepaws in a given trial by an observer blind to the treatment. The total number of forelimb placements was recorded. Data were expressed according to the following equation: (the number of contralateral forelimb movements)/(total number of forelimb movements $+[1 / 2]$ both forelimb movements $) \times 100 \%$ (Schallert, 2006). For the vibrissae test, the observer, blind to the treatment, counted the number of times the rat responded to unilateral vibrissae stimulation by tapping its forepaw on the surface of the counter against which the vibrissae were touched (Schallert, 2006). Data were expressed as the number of successful forepaw placements per 10 vibrissae stimulations.

Abnormal involuntary movements. The rating scale for AIMs is based on that used by Steece-Collier et al. $(2003,2009)$ and Soderstrom et al. $(2008,2010)$. AIMs were rated three times per week (Wednesday through Friday; Fig. 1). Each rat was observed for $2 \mathrm{~min}$, precisely $40 \mathrm{~min}$ after the L-DOPA injection, a time that corresponds to peak-dose dyskinesia. A cumulative score for total AIMs was calculated from the product of the intensity $(0-3 ; 0=$ no expression, $1=$ mild expression, $2=$ moderate expression, $3=$ severe expression $)$ and the frequency $(0-3 ; 0=$ no expression, $1=$ expression $<50 \%$ of the time, $2=$ expression $>50 \%$ of the time and $3=$ constant expression) of the individual rating category (Steece-Collier et al., 2003, 2009; Soderstrom et al., 2008, 2010).

\section{Morphological and synaptic studies}

Rats were killed $72 \mathrm{~h}$ following the final L-DOPA injection and AIMs recording. They were deeply anesthetized with sodium pentobarbital (3 $\mathrm{ml} / \mathrm{kg}$, i.p.) and transcardially perfused with $10 \mathrm{ml}$ of $0.1 \mathrm{M} \mathrm{PBS}$, followed by $50 \mathrm{ml}$ of $3.75 \%$ acrolein (Polysciences) in buffered $2 \%$ paraformaldehyde, $\mathrm{pH} 7.4$, and then $200 \mathrm{ml}$ of buffered $2 \%$ paraformaldehyde alone. All solutions were made fresh, and the perfusion rate was measured and kept constant. The brains were removed and postfixed for $1 \mathrm{~h}$ in buffered $2 \%$ paraformaldehyde.

Tissue preparation for TH, VGluT1, and VGluT2 immunohistochemistry. Brains were blocked twice to include the entire midbrain and the entire striatum. Coronal sections through the entire midbrain were cut at $60 \mu \mathrm{m}$ on a freezing microtome, after sinking the block for $24 \mathrm{~h}$ in a $30 \%$ sucrose solution. The striatum was cut at $60 \mu \mathrm{m}$ on the same day as the perfusion, using a vibratome (The Vibratome Company), and the sections were collected serially into numbered 24 -well cell culture plates with $0.1 \mathrm{M} \mathrm{PB}$. Following a random selection of the first section, systematic uniform sampling (as described by Mayhew, 1996; Mouton et al., 2002) was used to select series of equally spaced sections for TH, VGluT1, and VGluT2 immunohistochemistry, and to estimate the total volume of the dorsal striatum.

Midbrain sections were incubated in mouse antibodies against $\mathrm{TH}$ (1:2000; Immunostar) for $24-48 \mathrm{~h}$ at $4^{\circ} \mathrm{C}$, followed by $2 \mathrm{~h}$ in biotinylated horse anti-mouse IgG (1:200; Vector Laboratories) with 3\% normal serum at room temperature (RT), and $1 \mathrm{~h}$ in avidin-biotin complex 
$(A B C)$. The sections were then reacted with $0.05 \% 3,3^{\prime}-$ diaminobenzidine (DAB) containing $0.01 \% \mathrm{H}_{2} \mathrm{O}_{2}$ for $10-15 \mathrm{~min}$ and rinsed thoroughly with $0.1 \mathrm{M} \mathrm{PB}$. Omitting the primary antibody produced no staining. Using the optical fractionator, every fifth section was selected for the stereological quantification of the number of $\mathrm{TH}^{+}$neurons in the SNc. The total number of $\mathrm{TH}^{+}$cells on the dopaminedepleted side of all 6-OHDA-lesioned rats was then compared with the total number unilaterally in the intact controls (sham/saline group).

Striatal sections were collected as follows: after the random start, every eighth section of the dorsal striatum was selected, yielding three series of 10 equally spaced sections. The first two series were collected for VGluT1 or VGluT2 immunostaining, and the third to estimate the total volume of the dorsal striatum $\left(V_{\text {ref }}\right)$ using a modified Cavalieri method (Bothwell et al., 2001). Sections were then incubated for $1 \mathrm{~h}$ in $10 \%$ normal goat serum followed by $72 \mathrm{~h}$ at $4^{\circ} \mathrm{C}$ in $0.1 \mathrm{M}$ PBS containing $3 \%$ normal goat serum and rabbit anti-VGluT1 antibodies (1:200; MAb Technologies) to label corticostriatal synapses, or rabbit anti-VGluT2 antibodies (1:2000; Synaptic Systems) to label thalamostriatal synapses. Sections were then incubated in biotinylated goat anti-rabbit IgG (1:200; Vector Laboratories) at RT followed by $\mathrm{ABC}$. The sections were reacted with $0.05 \% \mathrm{DAB}$ containing $0.01 \% \mathrm{H}_{2} \mathrm{O}_{2}$ for $10-15 \mathrm{~min}$ and rinsed thoroughly with $0.1 \mathrm{M}$ PB.

Tissue preparation for the electron microscope. Sections were fixed in $2 \%$ osmium tetroxide diluted in $0.1 \mathrm{M} \mathrm{PB}$ for $45 \mathrm{~min}$ at RT in the dark, dehydrated with ascending series of alcohols, and placed in a mixture of epoxy resin and propylene oxide (1:1) overnight. The sections were then flat embedded in epoxy resin (a mixture of Embed 812, dodecenyl succinic anhydride, nadic methyl anhydride, and benzyldimethylamine; Electron Microscopy Sciences) between two sheets of Aclar Fluorohalocarbon film (Ted Pella). The epoxy resin was polymerized at $80^{\circ} \mathrm{C}$ for $10-14 \mathrm{~d}$. An area of known size $(0.5 \times 0.5 \mathrm{~mm})$ was cut out of paper (Calverley et al., 1988) and dropped onto an atlas image of the dorsal striatum (Paxinos and Watson, 1998). This was followed by cutting out a piece of tissue $\left(1 \mathrm{~mm}^{2}\right)$ from the same location in the dorsal striatum as the paper square on the atlas. The tissue was mounted on a resin block and sectioned with an ultramicrotome (EMUC6; Leica Microsystems) into ultrathin sections (silver, 60-70 nm), mounted on Formvar-coated copper slot grids, and stained with uranyl acetate and lead citrate before observation. All electron microscopy (EM) micrographs were taken in a JEOL JEM-1230 electron microscope, equipped with a Hamamatsu ORCA-HR CCD Camera (AMT XR-60 imaging system). Each sample that was cut and photographed had an equal chance of being included in the reference volume, as required by the disector analysis (Coggeshall, 1992).

The specificity of the VGluT antibodies was assessed by incubating sections of the striatum through the entire incubation protocol but with the omission of the primary antibodies. The cortex and thalamus were also included in these sections as positive controls for the VGluT transporters. No staining was evident in the striatum, cortex or thalamus. In addition, preabsorption with the VGluT1 peptide blocks detection of the VGluT1 band on a Western blot (MAb Technologies).

Preincubation of VGluT2 antibodies with the corresponding synthetic peptide (Strep-Tag Fusion protein containing amino acid residues 456582 of rat VGluT2, catalog \#135-4P; Synaptic Systems) results in negative immunolabeling (Wouterlood et al., 2012).

Antibody penetration. Antibody penetration for the EM studies was limited to the top $0.5 \mathrm{~mm}$ of each section. Therefore, ultramicrotome sections were taken only from the most superficial part of the block, approximately the top $300 \mu \mathrm{m}$. After sections were placed on copper slot grids, a thick section was cut and observed in the light microscope. If labeled structures could be seen in that section, the ultramicrotome sections were therefore taken from within the zone of antibody penetration. All sections photographed in the EM contained labeled boutons and were within the antibody penetration zone.

Stereological analysis of synapses. Each series of four electron micrographs, captured at 25,000× magnification, were collected 15 times (Fig. 2). Each series was spaced two widths of the EM screen from the previous four micrographs. The analysis was thus performed on 60 EM micrographs per block ( 15 sites per ultrathin section $\times 4$ ultrathin serial sec- tions per block; Fig. 2). We analyzed three blocks per animal and 180 disectors per animal (1080 disectors per group). The total number of synapses was estimated using a disector height of $60-70 \mathrm{~nm}$; the disector height was equal to the average thickness of folds in the ultrathin sections (De Groot, 1988). A rectangular unbiased counting frame $\left(32.02 \mu \mathrm{m}^{2}\right)$, which was outlined with two inclusion (dashed) and two exclusion (solid, extending above and below the square to infinity) lines, was centered on each of the EM micrographs (Fig. 2). Synapses that fell within the counting frame or on the inclusion, but not the exclusion, lines were counted. We counted "tops" of synapses in each series of ultrathin sections. Every section was used as a "reference" and again as a "look-up" section. The synapse top was counted in the reference section when it did not appear in the look-up section and vice versa. Slides, sections, and grids were always coded so that the investigator was blind to the identity of the groups. As previously described (Morshedi et al., 2009; Figge et al., 2012) and in accordance with well recognized criteria (Peters et al., 1991), synapses were identified by the accumulation of at least three presynaptic vesicles close to the synaptic cleft, and the presence of a cleft with parallel, thickened presynaptic and postsynaptic membranes and darkened content. Asymmetric synapses were identified by their postsynaptic density, which is $2.5-3$ times thicker than the presynaptic density. Boutons were classified as multisynaptic [multisynaptic bouton (MSB)] if they contacted more than one completely separate, independent target enclosed in its own plasma membrane. The associated postsynaptic targets were identified as somata, dendrites, or spines, as previously described (Morshedi et al., 2009; Figge et al., 2012) using recognized criteria (Peters et al., 1991). Some targets could not be identified if the ultrastructure was damaged and were labeled with a question mark.

The number of asymmetric inputs to individual spines was also counted using the physical disector (Fig. 2). The number of multisynaptic spines (i.e., spines that received more than one asymmetric contact) was estimated for rats in the control, 6-OHDA, and dyskinetic ${ }^{+}$groups (i.e., parkinsonian rats treated with L-DOPA that exhibited severe AIMs) and the dyskinetic ${ }^{-}$group (i.e., parkinsonian rats treated with L-DOPA that exhibited mild or no AIMs) and correlated with morphological MSN analysis (see below). The following formula was used to estimate the total number of synapses $(N)$ onto postsynaptic structures: $N=N_{\mathrm{v} / \text { syn }} \times V_{\text {ref, }}$ where $N_{\mathrm{v} / \text { syn }}$ is the mean synaptic density (synapses per cubic micrometer) and $V_{\text {ref }}$ is the reference volume. Estimation of the mean synaptic density $\left(N_{\mathrm{v} / \text { syn }}\right)$ was calculated using the formula $N_{\mathrm{v} / \text { syn }}=\Sigma Q_{-}{ }_{\text {syn }} /(h \times$ $A$ ) adapted from Sterio (1984) and de Groot and Bierman (1986), where $Q_{-}{ }_{\text {syn }}$ is the synapses present in the reference section but not in the look-up section (tops); $h$ is the height of the disector, which is the distance (in micrometers) between disector planes (section thickness); and $A$ is the sample area (in square micrometers). To estimate ultrathin section thickness $(h)$ using Small's minimal fold method (Small, 1968; De Groot, 1988), at least three folds from each of the sections were used for analysis and photographed at $10,000 \times$ magnification. Section thickness (h) was then estimated as half the mean width of the measured folds.

The boundaries of $V_{\text {ref }}$ were established from an adjacent series of 10 sections using the Cavalieri method (Coggeshall, 1992). These $10 \mathrm{sec}-$ tions were stained with cresyl violet, dehydrated, and coverslipped. The volume was estimated using a Nikon E400 microscope equipped with Stereo Investigator software (MBF Bioscience). The dorsal striatum was outlined on each section. The following formula was then used to determine the $V_{\text {ref }}$ (in cubic micrometers): $V_{\text {ref }}=a \times t \times s$, where $a=$ mean area (in square micrometers) of the striatum, $t=$ mean thickness (in square micrometers) of the vibratome sections, and $s=$ the total number of sections through the striatum $(\sim 85-90)$.

Synapse sampling bias. The physical disector is a design-based stereological technique that allows for the counting of particles (in this case, synapses) in three-dimensional space from two-dimensional sections (micrographs). This method uses parallel sections of a known thickness, at a known distance apart, and in a known unit of volume (Braendgaard and Gundersen, 1986; Gundersen et al., 1988; Howard and Reed, 1998; Mouton et al., 2002). All synapses in the dorsal striatum are thus given an equal and independent chance of being selected, and the estimates of the numbers of synapses are independent of their size, shape, spatial orientation, and spatial distribution (Schmitz and Hof, 2007). To guarantee 

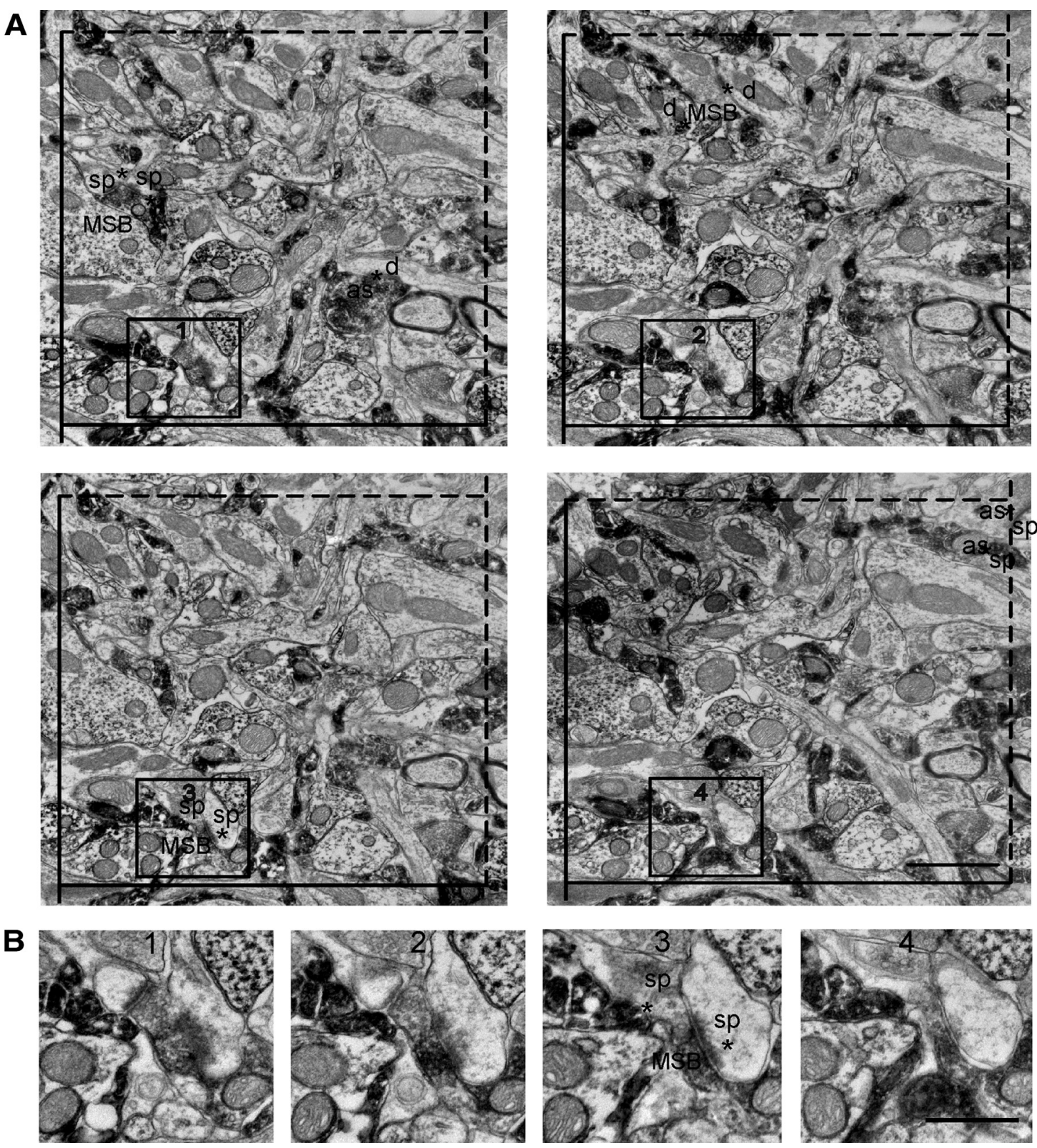

Figure 2. Illustrations of the physical disector analysis. A, Set of four serial EM micrographs overlaid with counting frames. Asterisks $(*)$ mark the tops of synapses. Tops were counted if they were within the counting frame or on the inclusion lines (dashed lines), but not the exclusion lines (solid lines). Each micrograph was used as both reference and look-up sections by analyzing synapses from the left top to right bottom photomicrograph and then again from the right bottom to left top photomicrograph. Synapses were only counted if they appeared in reference but not the look-up section. Tops of synapses are labeled with an asterisk and as asymmetric (as) or multisynaptic (MSB). The postsynaptic target [spine (sp), dendrite (d)] is also labeled. Multisynaptic spines are not shown. Scale bar, $1 \mu \mathrm{m}$. $\boldsymbol{B}$, High-power views of the areas within the numbered boxes (1-4) drawn on each of four sections in $\boldsymbol{A}$. The boxes in $\boldsymbol{B}$ illustrate an MSB that was counted because it did not appear in all four sections. Scale bar, $500 \mathrm{~nm}$.

that synapses are afforded equal chances of being counted, each disector pair must be randomly located within the defined region. Recent work has suggested that in the rat dorsal striatum, there are density gradients for VGluT1 and VGluT2 boutons, and differences in their density in the patch and matrix compartments (Wouterlood et al., 2012). The physical disector is therefore the most appropriate method to count these synapses, since its approach can prevent oversampling of the regions where gradients exist and ensure that patch and matrix compartments have an equal chance of being sampled for every rat (Mayhew, 1996).

Tissue preparation for Golgi-Cox studies. Three separate groups of male Sprague-Dawley rats were prepared for the Golgi-Cox studies: control (untreated, $n=6$ ), parkinsonian (6-OHDA lesion, $n=6$ ); and dyskinetic $^{+}(n=5)$. These groups were handled, anesthetized, surgically lesioned, and behaviorally measured following the same schedule as described above and in Figure 1, except that there was a 2 week, rather than a 3 week, delay between the lesion and the L-DOPA treatments. Following L-DOPA or saline treatments for 4 weeks, rats were deeply anesthetized and transcardially perfused with $200 \mathrm{ml}$ of heparinized, RT, $0.9 \%$ saline, and brains were blocked in half coronally at the level of the hypothalamus using a single-edged razor blade. The result was a block that measured $\sim 7 \mathrm{~mm}$ (rostral-to-caudal length) and was subjected to a modified Golgi-Cox impregnation method (Levine et al., 2013). The rostral portion of block containing the striatum was placed into GolgiCox fixative solution and impregnated following details in Levine et al. (2013). The brains were then sectioned on a vibrating microtome (VT1000S; Leica Microsystems) at a thickness of $100 \mu \mathrm{m}$, and sections were collected in a $1 \%$ solution of potassium dichromate. The sections were mounted onto gel-coated slides; placed in a solution of $28 \%$ ammonium hydroxide $\left(\mathrm{NH}_{4} \mathrm{OH}\right.$ in distilled water, Sigma-Aldrich) for $30 \mathrm{~min}$ at RT; followed by rinsing in tap water, then in 15\% Kodak fixers (Poly- 
max T Fixer; Electron Microscopy Sciences), and finally in tap water. The slides were then dehydrated in an ascending series of alcohols, cleared in xylene, and coverslipped with DPX mountant (Fluka BioChemika; see also Levine et al., 2013).

We performed computer-assisted 3-dimensional reconstructions (Neurolucida; MBF Bioscience) of the Golgi-Cox striatal MSNs from the dorsal parts of the dorsal striatum. Golgi-impregnated neurons were identified in the dorsal, commissural, and precommissural striatum. Each entire dendritic tree of MSNs in a 100- $\mu$ m-thick section was traced thru the $x_{-}^{-}, y^{-}$, and $z$-axes in impregnated neurons using the Neurolucida software (MBF Bioscience; $n=3$ neurons per rat). MSNs were first visualized at low-power magnification and selected for reconstruction based on the quality of Golgi-Cox impregnation. Neurons selected for analysis were required to have at least four primary dendrites that radiated from the soma in an arc encompassing $\sim 360^{\circ}$ and to not have excessive dendritic overlap with neighboring cells. Spine density and phenotype (i.e., mushroom, thin, or branched), and dendrite branching, length, and surface area were quantified. The following formula was used to calculate dendritic surface area: surface area $=\pi\left(R_{1}+R_{2}\right) V \mathrm{~h}^{2}+$ $\left(R_{1}-R_{2}\right)^{2}$, where $R_{1}$ is the radius at the start of that dendritic segment, $R_{2}$ is the radius at the end of the segment and $h$, the length. The data were compared statistically for total spine density, dendritic length, and surface area, and for these same features within proximal (i.e., branch orders 1-3) and distal (i.e., branch orders 4-8) dendritic branches. Reconstructions were performed at both institutions (Michigan State University and Rosalind Franklin University) by investigators blind to the treatment of the animals.

\section{Data presentation and statistical analysis}

All data were first tested for normality by a Shapiro-Wilk test. The cylinder and vibrissae tests were analyzed with a Kruskal-Wallis one-way ANOVA on ranks followed by a Dunn's multiple-comparison test. AIM scores, striatal volume, and stereological and neuronal reconstruction data were analyzed with a one-way, two-way, or repeated-measures ANOVA. The correlation between the extent of the lesion and the severity of AIMs was analyzed with a Pearson $r$ test. The coefficient of error (CE), a measure of sampling error, was calculated for each animal and group for each stereological analysis.

\section{Results}

\section{Lesion verification and behavioral measurements}

The initial evaluation of the 6-OHDA lesion status was examined with drug-free cylinder and vibrissae tests. For both these tests, the Kruskal-Wallis one-way ANOVA on ranks revealed a main effect for the lesion (cylinder test: $H_{(5)}=55.513, p<0.001$; vibrissae test: $\left.H_{(5)}=131.916, p<0.001\right)$ and a significant deficit in the contralateral forepaw use for the 6-OHDA-lesioned rats in the cylinder test ( 2 weeks postlesion, $p<0.05$; 3 weeks postlesion, $p<0.05$ ) and in the vibrissae test ( 2 weeks postlesion, $p<0.05 ; 3$ weeks postlesion, $p<0.05$ ).

In the cylinder test, all rats used both forepaws equally to make contact with the cylinder wall before 6-OHDA surgery (contralateral forepaw contacts, $50.2 \pm 0.01 \%$; ipsilateral forepaw contacts, $49.8 \pm 0.01 \%$ ). Following the lesion, the parkinsonian rats showed a significant deficit in contralateral paw contacts at 2 weeks $(24.2 \pm 0.03 \%)$ and 3 weeks $(21.7 \pm 0.03 \%)$ postlesion compared with the contralateral paw contacts in the control group at 2 weeks $(47.9 \pm 0.03 \%$ contacts, $p<0.05)$ and 3 weeks $(49.8 \pm 0.02 \%$ contacts, $p<0.05)$ postlesion. The same comparisons were conducted with the vibrissae test. Before surgery, all rats showed a $100 \%$ tap response to vibrissae stimulation for both left and right forepaws (successful taps per 10 trials, $10 \pm 0$ ). Control rats maintained a $100 \%$ tap response for both forepaws. Rats receiving a 6-OHDA lesion showed a significant impairment on the side contralateral to the lesion compared with that of the ipsilateral side at 2 weeks (successful taps of the contralateral
Table 1. Stereological estimates of the number of $\mathrm{TH}^{+}$neurons in the SNc

\begin{tabular}{lccc}
\hline & $\begin{array}{l}\text { Mean total number } \\
\text { of } \mathrm{TH}^{+} \text {neurons } \\
\text { in the SNc (unilateral) }\end{array}$ & CE & $\begin{array}{l}\mathrm{TH}^{+} \text {neuron } \\
\text { loss as percent of } \\
\text { control SNc }\end{array}$ \\
\hline Control (sham/saline) & $11,138 \pm 170$ & 0.09 & \\
6-OHDA $^{-0}$ & $630 \pm 247^{* * * *}$ & 0.51 & $94.0 \pm 2.4 \%$ \\
Dyskinetic $^{-}$ & $398 \pm 141^{* * * *}$ & 0.57 & $96.2 \pm 1.4 \%$ \\
Dyskinetic $^{+}$ & $360 \pm 149^{* * * *}$ & 0.68 & $96.6 \pm 1.4 \%$ \\
\hline
\end{tabular}

Stereological estimates of the total number of $\mathrm{TH}^{+}$neurons in the SNc. Values are given as the mean $\pm \mathrm{SE}$. ${ }^{* * * *} p<0.001$ compared to the control group.

paw/10 trials, $1.60 \pm 0.51, p<0.05$ ) and 3 weeks (successful taps of the contralateral paw/10 trials, $1.90 \pm 0.40, p<0.05$ ) postlesion.

Final verification of lesion status was done by estimating the total number of $\mathrm{TH}^{+}$neurons in the $\mathrm{SNc}$ using the optical fractionator (Stereo Investigator; MBF Bioscience) and by examining the pattern of $\mathrm{TH}^{+}$fibers in the striatum. Rats with a 6-OHDA lesion lost $>90 \%$ of all dopaminergic neurons from the SNc (one-way ANOVA $F_{(3,17)}=509.356, p<0.001$; Table 1). There was no difference in the $\mathrm{SNc} \mathrm{TH}^{+}$neuron loss between the rat groups that received the 6-OHDA lesion $(p>0.05)$, and no difference in neuron loss between rats that were dyskinetic ${ }^{+}$and those that were dyskinetic ${ }^{-}(p>0.05$, Table 1$)$. The striatum displayed a typical pattern of $\mathrm{TH}^{+}$fiber loss, in that the dorsal striatum was completely devoid of fibers (Fig. 3).

All L-DOPA-treated, 6-OHDA-lesioned rats were rated for the severity of their AIMs. Rats with severe AIMs $\left(\right.$ dyskinesia $\left.^{+}\right)$displayed axial, orofacial, and limb AIM cumulative severity scores that ranged from 10 to 25 . Rats with mild AIMs (dyskinesia ${ }^{-}$) had cumulative severity scores that ranged from 0 to 2 . There was also a group of rats with moderate, cumulative severity scores that fell between the severe and mild scores. The latter animals displayed hyperkinetic but no dystonic movements. We eliminated the moderate group from further analysis and examined only the dyskinetic $^{+}$and dyskinetic ${ }^{-}$groups. In anatomical studies, it is important to be able to relate an anatomical substrate to a specific behavioral outcome. Thus, the behavior must be distinct and not on a continuum. Such differences can only be detected by studying animals with fully separate score ranges on a given rating scale (Meredith et al., 2000).

We measured the severity of AIMs and their severity over time (Fig. 4A; two-way repeated-measures ANOVA, main effect of AIMs severity: $F_{(1,71)}=245.97, p<0.001$; main effect of time: $F_{(8,71)}=8.972, p<0.001$; AIMs severity $\times$ time interaction: $\left.F_{(8,71)}=5.969, p<0.001\right)$. Dyskinetic ${ }^{+}$animals showed significantly higher scores at each rating session and at each session over time compared with the dyskinetic ${ }^{-}$group ( $p$ values $<0.001$; Fig. $4 A$ ). In addition, only the dyskinetic ${ }^{+}$group showed that AIM scores were greater at all time points in sessions 2-9 than at the first rating session ( $p$ values $<0.001$ ). Thus, the AIMs increased in intensity over time for the dyskinetic ${ }^{+}$group. In addition, there was no correlation between the severity of AIMs and the extent of the lesion (Fig. 4B).

\section{Reference volumes do not differ between groups}

We used the Cavalieri method to estimate the volume of the striatum (Coggeshall, 1992). There was no difference in striatal volume between intact controls (saline or L-DOPA treatments) and lesioned groups (one-way ANOVA, $F_{(4,25)}=2.393 p=0.08$; Table 2). 
Corticostriatal and thalamostriatal synapses are differentially distributed in the control striatum, and L-DOPA treatment does not alter that distribution

We began the analysis by estimating the total number of VGluT1-immunopositive $\left(\mathrm{VGluT}^{+}{ }^{+}\right.$), VGluT2-immunopositive $\left(\mathrm{VGluT}^{+}{ }^{+}\right.$), and unlabeled asymmetric (presumed excitatory) synapses in the dorsal striatum of control rats (Fig. 2). The VGluT1 ${ }^{+}$terminals comprised $\sim 38 \%$ of all asymmetric contacts, and the VGluT2 ${ }^{+}$ synapses comprised $\sim 20 \%$, with the remainder being unlabeled. The VGluT1 ${ }^{+}$ and VGluT2 ${ }^{+}$immunoreaction product (DAB) was found in terminals from the cortex and thalamus, respectively, and did not colocalize in the striatum (Lacey et al., 2005). This indicates that $\sim 42 \%$ of all asymmetric endings are VGluT1 ${ }^{-}$or VGluT2 ${ }^{-}$, as demonstrated by others (Lacey et al., 2005), and could therefore originate from other regions, such as the serotonergic afferents from the raphé (Soghomonian et al., 1989; Descarries et al., 1992) or from cholinergic interneurons, both of which have been shown to express vesicular glutamate transporter 3 in the striatum (Gras et al., 2002; Fujiyama et al., 2004). We then examined the target specificity of asymmetric synapses (single synaptic contacts, not MSBs) in the control (sham/saline) striatum by quantifying the total number of $\mathrm{VGluT}^{+}{ }^{+}$(corticostriatal) and VGluT2 $^{+}$(thalamostriatal) terminals and the number contacting spines and dendrites (Fig. 5). We found that VGluT1 ${ }^{+}$afferents form the great majority of their asymmetric contacts onto spines rather than dendritic shafts. In contrast, VGluT2 ${ }^{+}$afferents also contact spines predominantly, but make more asymmetric contacts with dendritic shafts than VGluT1 ${ }^{+}$synapses (Fig. 5). These data are very similar to earlier findings by others (Lacey et al., 2005; Moss and Bolam, 2008).

L-DOPA treatment does not affect corticostriatal or thalamostriatal synapses in intact animals, but when administered after the parkinsonian lesion L-DOPA dramatically increases corticostriatal synapses

It is important to control for the effects of the drug, since L-DOPA could be responsible for changes in synapse distribution or postsynaptic targets in intact animals or following the dopaminedepleting lesion in the dyskinetic ${ }^{-}$group. Therefore, to determine whether L-DOPA alters synapses, we compared the effects of L-DOPA on the total number of corticostriatal and thalamostriatal synapses (two-way ANOVA; VGluT1 ${ }^{+}$: main effect of L-DOPA, $F_{(1,22)}=6.451, p=0.019$; main effect of lesion, $F_{(1,22)}=9.380, p=0.006$; no interaction between L-DOPA and lesion, $F_{(1,22)}=4.016, p>0.05$; VGluT2 ${ }^{+}$: no main effect of L-DOPA, $F_{(1,22)}=0.987, p>0.05$; no effect of lesion, $F_{(1,22)}=$ $1.834, p>0.05$; no interaction between L-DOPA and lesion, $\left.F_{(1,22)}=1.941, p>0.05\right)$. There was no L-DOPA effect within the sham-lesioned groups for corticostriatal or thalamostriatal total synapses (sham/saline vs sham/L-DOPA: VGluT1 ${ }^{+}, p>0.05$; VGluT2 $^{+}, p>0.05$; Fig. $6 A$ ). The parkinsonian lesion (6$\mathrm{OHDA} /$ saline) significantly reduced the total number of corticostriatal synapses compared with controls (sham/saline, VGluT1 $\left.{ }^{+}, p=0.003\right)$, but L-DOPA treatment of parkinsonian rats (6-OHDA/L-DOPA) greatly increased the total number of corticostriatal endings compared with those in the parkinsonian

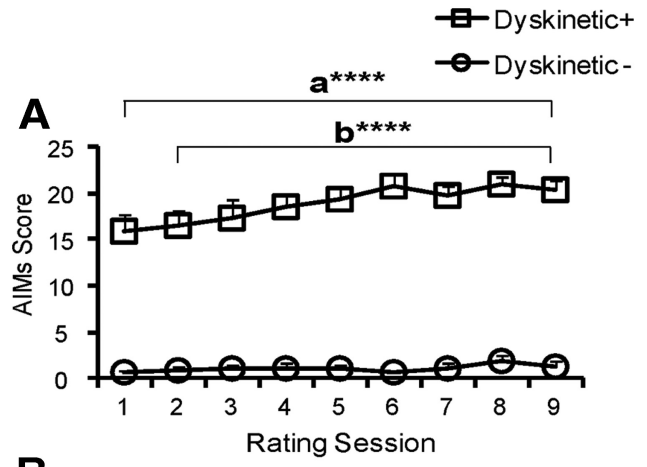

B
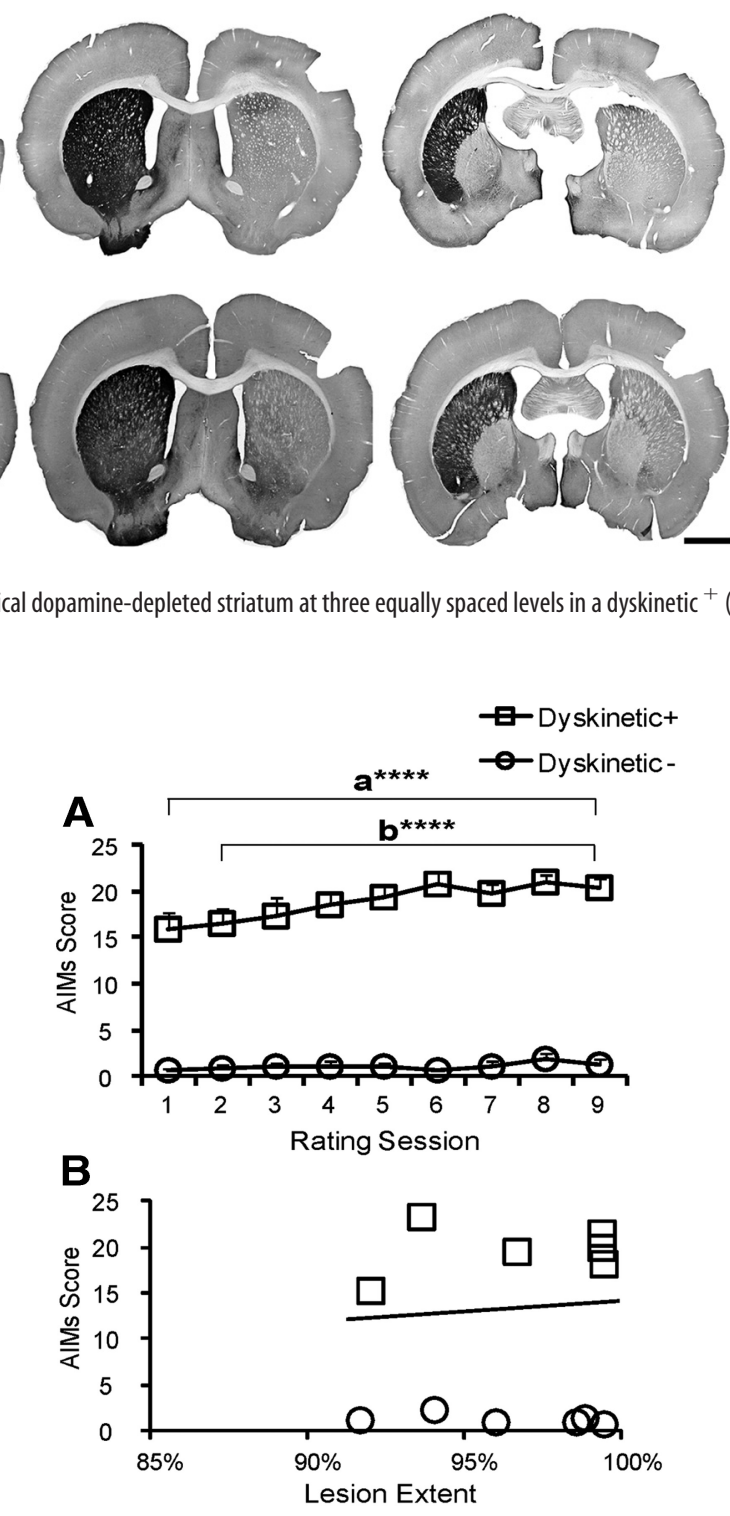

Figure 4. $\quad A$, AlMs scores for the dyskinetic ${ }^{+}(n=6)$ group were significantly greater than those for the dyskinetic ${ }^{-}(n=6)$ group at all time points examined and were greater at all time points (sessions 2-9) than at rating session 1 for the dyskinetic ${ }^{+}$but not the dyskinetic ${ }^{-}$ group. $\boldsymbol{B}$, The graph illustrates a comparison between the extent of the lesion ( $x$-axis) with the severity of the AIMs ( $y$-axis). There is no significant correlation between the lesion status and AlMs severity (Pearson's $r=0.49$ ). ${ }^{* * *} p<0.001$.

\section{Table 2. Striatal volume}

\begin{tabular}{lll}
\hline Group & $V_{\text {ref }}\left(\mathrm{mm}^{3}\right)$ & CE \\
\hline Control (Sham/Saline) & $30.14 \pm 0.7$ & 0.02 \\
Control (Sham/L-DOPA) & $28.78 \pm 1.38$ & 0.05 \\
6-OHDA & $27.11 \pm 1.16$ & 0.04 \\
Dyskinetic $^{-}$ & $27.12 \pm 0.42$ & 0.02 \\
Dyskinetic $^{+}$ & $29.37 \pm 0.77$ & 0.03 \\
\hline
\end{tabular}

Cavalieri estimates of the reference volume $\left(V_{\text {ref }} \pm \mathrm{SE}\right)$ and the CE for each group.

L-DOPA-naive group (6-OHDA/saline, VGluT1 ${ }^{+}, p=0.002$; Fig. 6A). The parkinsonian lesion (6-OHDA/saline) did not alter the total number of thalamostriatal $\left(\mathrm{VGluT}_{2}{ }^{+}\right.$) synapses compared with controls. Moreover, L-DOPA treatment of parkinsonian rats (6-OHDA/L-DOPA) did not change the total number of thalamostriatal $\left(\mathrm{VGluT}_{2}{ }^{+}\right.$) endings compared with those in the 
A Corticostriatal

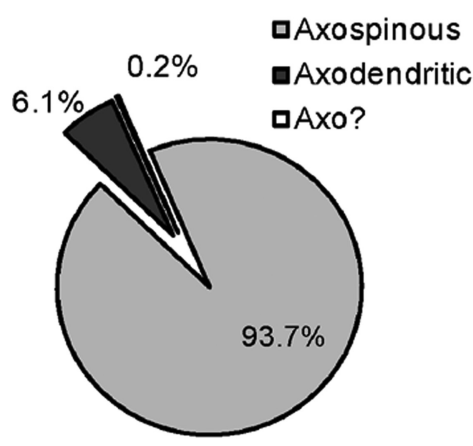

Figure 5. Pie charts illustrate the proportions of targets for corticostriatal $(\boldsymbol{A})$ and thalamostriatal $(\boldsymbol{B})$ synapses in intact control animals. Axospinous, synapses onto spines; Axodendritic, contacts onto dendrites; Axo?, contacts onto undetermined targets.

\section{B Thalamostriatal}

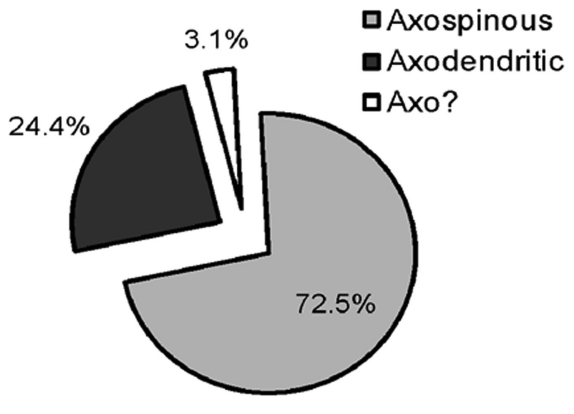

parkinsonian L-DOPA-naive group (6-OHDA/saline). Overall, these data indicate that corticostriatal, but not thalamostriatal, synapses had been added by L-DOPA treatment after the lesion (Fig. 6A).

We next determined the effects of L-DOPA on corticostriatal and thalamostriatal axospinous synapses (two-way ANOVA; VGluT1 $^{+}$: no effect of L-DOPA, $F_{(1,22)}=3.961, p>0.05$; main effect of lesion, $F_{(1,22)}=7.991, p=0.010$; no interaction between L-DOPA and lesion, $F_{(1,22)}=2.922, p>0.05$; VGluT2 ${ }^{+}$: no effect of L-DOPA, $F_{(1,22)}=0.987, p>0.05$; no effect of lesion, $F_{(1,22)}=$ 1.834, $p>0.05$; no interaction between L-DOPA and lesion, $F_{(1,22)}=1.941, p>0.05$ ) and axodendritic synapses (two-way ANOVA; VGluT $1^{+}$: main effect of L-DOPA, $F_{(1,22)}=10.105, p=$ 0.004 ; no effect of lesion, $F_{(1,22)}=0.913, p>0.05$; no interaction between L-DOPA and lesion, $F_{(1,22)}=0.474, p>0.05$; VGluT2 ${ }^{+}$: no effect of L-DOPA, $F_{(1,22)}=0.809, p>0.05$; no effect of lesion, $F_{(1,22)}=0.265, p>0.05$; significant interaction between L-DOPA and lesion, $\left.F_{(1,22)}=5.196, p=0.033\right)$. There was no L-DOPA effect within the sham-lesioned control groups for corticostriatal or thalamostriatal axospinous or axodendritic synapses (sham/ saline vs sham/L-DOPA: VGluT1 ${ }^{+}, p>0.05$; VGluT2 ${ }^{+}, p>$ 0.05; Fig. $6 A$ ). There was, however, a significant difference between the parkinsonian groups (6-OHDA/saline vs 6-OHDA/ bpL-DOPA; Fig. 6A). The lesioned L-DOPA-naive group (6OHDA/saline) had significantly reduced the total number of corticostriatal synapses onto spines $\left(\mathrm{VGluT}^{+}, p=0.01\right)$ but not onto dendrites (VGluT1 ${ }^{+}, p>0.05$ ) compared with controls (sham/saline), and L-DOPA treatment of the parkinsonian rats (6-OHDA/L-DOPA) significantly increased the number of VGluT1 ${ }^{+}$endings onto spines compared with that in the parkinsonian L-DOPA-naive group (6-OHDA/saline, VGluT1 ${ }^{+}$, $p=0.009$ ), restoring the total axospinous endings to the level of controls (Fig. 6A). In addition, L-DOPA treatment significantly increased the number of corticostriatal synapses onto dendrites compared with that in the parkinsonian L-DOPAnaive group (VGluT1 ${ }^{+}, p=0.007$ ). While thalamostriatal axospinous and axodendritic synapses were not lost after the 6-OHDA lesion (VGluT2 ${ }^{+}, \mathrm{p}>0.05$ ), L-DOPA treatment did significantly increase the number of contacts onto dendrites compared with that in the parkinsonian L-DOPA-naive group (VGluT2 ${ }^{+}, p=0.023$; Fig. $6 A$ ).

It then became important to establish whether these synaptic changes following the L-DOPA treatment are due to the development of dyskinesias per se. Therefore, we compared the dyskinetic ${ }^{+}$ and dyskinetic ${ }^{-}$groups separately to parkinsonian L-DOPA-naive (6-OHDA/saline) and control (sham/saline) groups (Fig. 6B,C).
Both the dyskinetic ${ }^{+}$and the dyskinetic rats showed a significant increase in the total number of corticostriatal synapses compared with the parkinsonian L-DOPA-naive group [one-way ANOVA; VGluT1 ${ }^{+}$: $F_{(2,13)}=16.680, p<0.001$; dyskinetic $^{+}$ group significantly increased compared with the parkinsonian L-DOPA-naive group (6-OHDA/saline), $p<0.001$; dyskinetic ${ }^{-}$group significantly increased compared with the 6-OHDA/saline group, $p=0.027]$. Neither the dyskinetic ${ }^{+}$nor the dyskinetic ${ }^{-}$rats showed a change in the total number of thalamostriatal synapses compared with the parkinsonian L-DOPA-naive group (one-way ANOVA; VGluT2 $\left.^{+}, F_{(2,13)}=2.068, p=0.16\right)$.

For corticostriatal synapses, the dyskinetic ${ }^{+}$, but not the dyskinetic $^{-}$rats, showed a significant increase in the total number of axospinous synapses (one-way ANOVA; VGluT1 ${ }^{+}$, main effect of dyskinesia status, $\left.F_{(2,13)}=12.74, p<0.001\right)$ and axodendritic terminals (one-way ANOVA; VGluT1 ${ }^{+}$, main effect of dyskinesia status, $\left.F_{(2,13)}=16.93, p<0.001\right)$ compared with the parkinsonian L-DOPA-naive group (6-OHDA/saline; Fig. $6 B$ ). When the thalamostriatal synapses were examined, neither the dyskinetic $^{+}$or dyskinetic ${ }^{-}$animals showed any change in the number of axospinous synapses (one-way ANOVA; VGluT2 ${ }^{+}, F_{(2,13)}=$ $1.736, p>0.05$ ) or axodendritic contacts (one-way ANOVA; VGluT2 $\left.^{+}, F_{(2,13)}=3.248, p=0.07\right)$ compared with the parkinsonian L-DOPA-naive (6-OHDA/saline) group (Fig. 6B).

The greatest corticostriatal synaptic changes occurred in the parkinsonian rats that were dyskinetic ${ }^{+}$(Fig. 6C). There was a significant increase in the total number of corticostriatal synapses [one-way ANOVA; VGluT1 ${ }^{+}$main effect of dyskinesia status, $F_{(2,13)}=4.378, p=0.035$; dyskinetic $^{+}$significantly greater than dyskinetic $^{-}, p=0.036$; but no difference from controls (sham/ saline), $p>0.05$ ], axospinous synapses [one-way ANOVA; VGluT1 ${ }^{+}$, main effect of dyskinesia status, $F_{(2,13)}=4.364, p=$ 0.035 ; dyskinetic $^{+}$significantly greater than dyskinetic ${ }^{-}, p=$ 0.042; but no difference from controls (sham/saline) $p>0.05$ ], and axodendritic synapses [main effect of dyskinesia status, $F_{(2,13)}=11.417, p=0.001 ;$ dyskinetic $^{+}$significantly greater than dyskinetic $^{-}, p=0.003$, and significantly greater than controls (sham/saline) $p=0.004]$ for the dyskinetic ${ }^{+}$group. For the thalamostriatal synapses, there was no difference among the dyskinetic $^{+}$, dyskinetic ${ }^{-}$, and control groups in the total number of contacts (one-way ANOVA; VGluT2 ${ }^{+}$, no effect of dyskinesia status, $\left.F_{(2,13)}=0.119, p>0.05\right)$, the number of axospinous contacts $\left(\right.$ VGluT2 ${ }^{+}$, no effect of dyskinesia status, $F_{(2,13)}=0.343$, $p>0.05$ ), or the number of axodendritic contacts (VGluT2 ${ }^{+}$, no effect of dyskinesia status, $H_{(2)}=0.647, p>0.05$; Fig. $6 C$ ).

\section{Multisynaptic boutons are lost in parkinsonian rats with or without dyskinesias}

Significant changes in the number of MSBs are an important indication of circuit modifications, such as remodeling (Rademacher et al., 2010). In the control group (sham/saline), VGluT1 ${ }^{+}$ and $\mathrm{VGluT}_{2}{ }^{+}$terminals occasionally contacted more than one target, documenting a small population of MSBs in control brains. These MSBs generally contacted two distinct spines, especially for the VGluT1 ${ }^{+}$afferents. However, a few MSBs that were

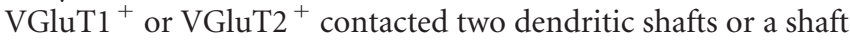
and a spine (see also Moss and Bolam, 2008). An insufficient 

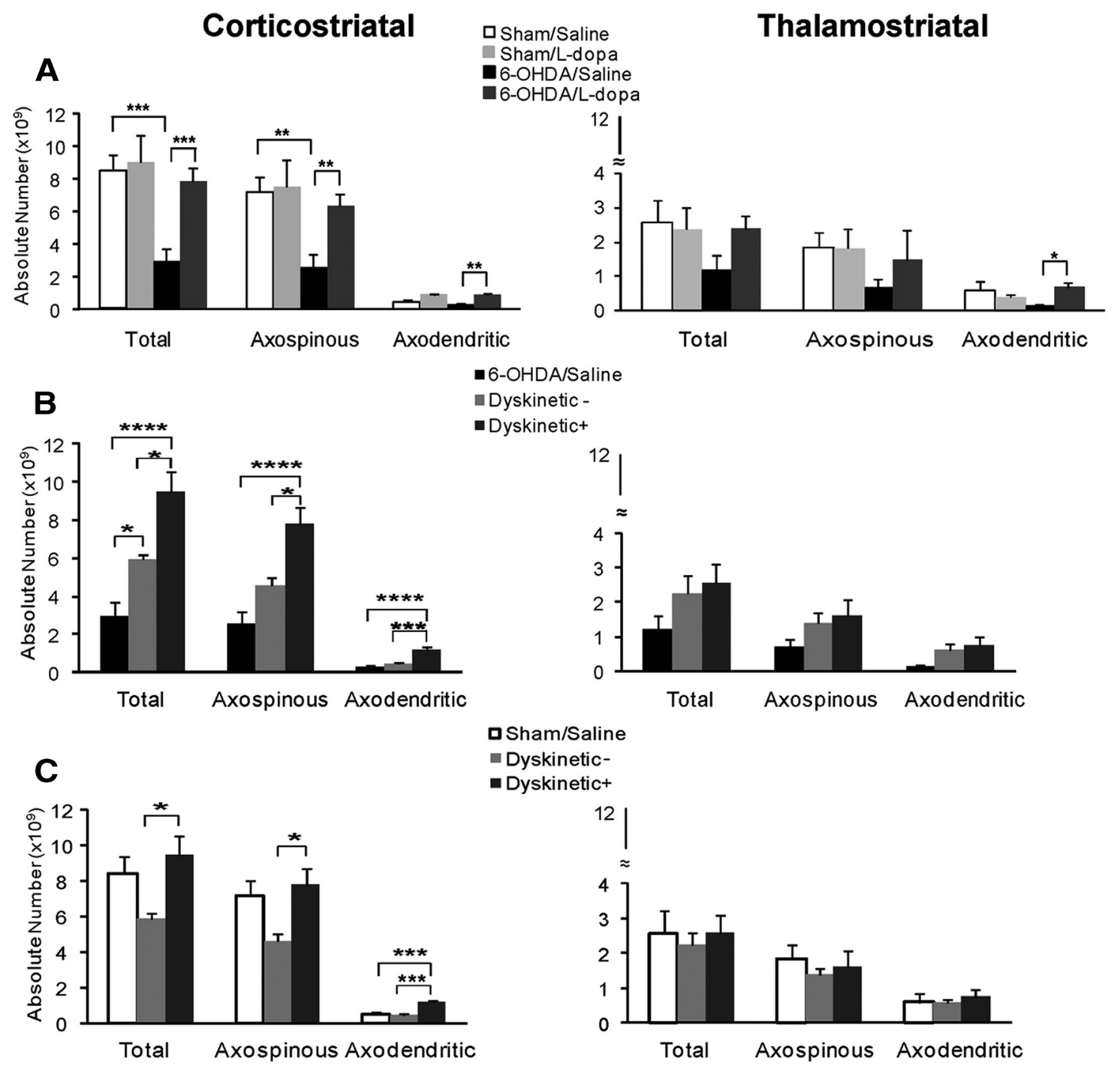

口Sham/Saline

Dyskinetic-

- Dyskinetic+

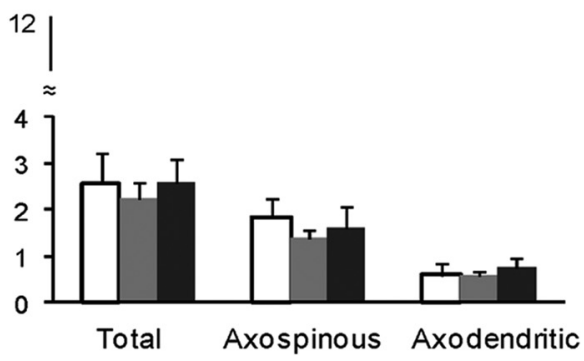

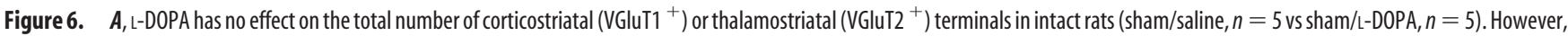
there is a loss of total VGluT1 ${ }^{+}$synapses and axospinous inputs in parkinsonian rats that were L-DOPA naive $(n=5)$ compared with controls (sham/saline and sham/L-DOPA), and a restoration of total VGluT1 ${ }^{+}$synapses and axospinous contacts in the parkinsonian group treated with L-DOPA $(n=11)$ compared with the parkinsonian, L-DOPA-naive rats. There is a significant increase in $\mathrm{VGluT1}^{+}$and VGluT2 ${ }^{+}$synapses contacting dendrites for the L-DOPA-treated lesioned group compared with the parkinsonian L-DOPA-naive group. $\boldsymbol{B}$, The bar graphs illustrate differences among the dyskinetic ${ }^{+}(n=6)$, dyskinetic ${ }^{-}(n=5)$, and parkinsonian L-DOPA-naive (6-OHDA/saline, $\left.n=5\right)$ groups for VGluT1 ${ }^{+}$and VGluT2 ${ }^{+}$contacts. The dyskinetic ${ }^{+}$group shows a significant increase in total, axospinous, and axodendritic synapses compared with the dyskinetic ${ }^{-}$and parkinsonian L-DOPA-naive groups for the corticostriatal contacts, but no difference for thalamostriatal synapses. C, The bar graphs illustrate differences among dyskinetic ${ }^{+}$, dyskinetic ${ }^{-}$, and intact control (sham/saline, $n=5$ ) groups. There is a significant increase in total, axospinous, and axodendritic corticostriatal synapses for the dyskinetic ${ }^{+}$group compared with the dyskinetic ${ }^{-}$group, and an increase in corticostriatal axodendritic contacts compared with the dyskinetic ${ }^{-}$and control groups. There were no differences between groups in the number of thalamostriatal synapses. ${ }^{*} p<0.05,{ }^{* *} p<0.01,{ }^{* * *} p<0.005,{ }^{* * * *} p<0.001$.

number of MSBs was detected among the thalamostriatal synapses to test for differences. Among corticostriatal MSBs and under all conditions of striatal dopamine depletion, regardless of dyskinesia status, the total number of corticostriatal $\left(\mathrm{VGluT1}^{+}\right)$ MSBs decreased significantly (two-way ANOVA; no effect of L-DOPA, $F_{(1,22)}=0.068, p>0.05$; main effect of lesion, $F_{(1,22)}=$ $24.094, p=0.003$; and no interaction between L-DOPA and le$\left.\operatorname{sion} F_{(1,22)}=3.561, p>0.05\right)$. Thus, regardless of treatment, the 6 -OHDA lesion significantly reduced the total number of corticostriatal MSBs $(p<0.001)$.

\section{Aberrant morphological plasticity of MSNs in dyskinetic ${ }^{+}$animals}

The restoration of axospinous and axodendritic corticostriatal synapses in the dyskinetic ${ }^{+}$animals led us to question how the substrate (MSNs) adapted to this change in wiring. Reconstructions of Golgi-impregnated neurons revealed typical MSN morphology. Specifically, there were from four to eight primary dendrites on each MSN, and proximal dendrites emerging from the soma were initially aspiny, with spines increasing in frequency from proximal to distal branch orders. The MSNs in the control striatum had an overall mean spine density of (8.5/10 $\mu \mathrm{m})$, and distal branches were more densely covered in spines $(8.9 / 10 \mu \mathrm{m})$ compared with proximal branches $(7.9 / 10 \mu \mathrm{m})$. As expected and, in support of the corticostriatal spine and synaptic loss seen in the 6- OHDA-lesioned animals previously (Ingham et al., 1989, 1998), there was a significant loss of spines for the parkinsonian rats (6-OHDA), regardless of their dyskinetic state (one-way ANOVA; $F_{(2,31)}=10.42, p<0.001$; parkinsonian significantly reduced compared with controls, $p<0.001$; and dys- 

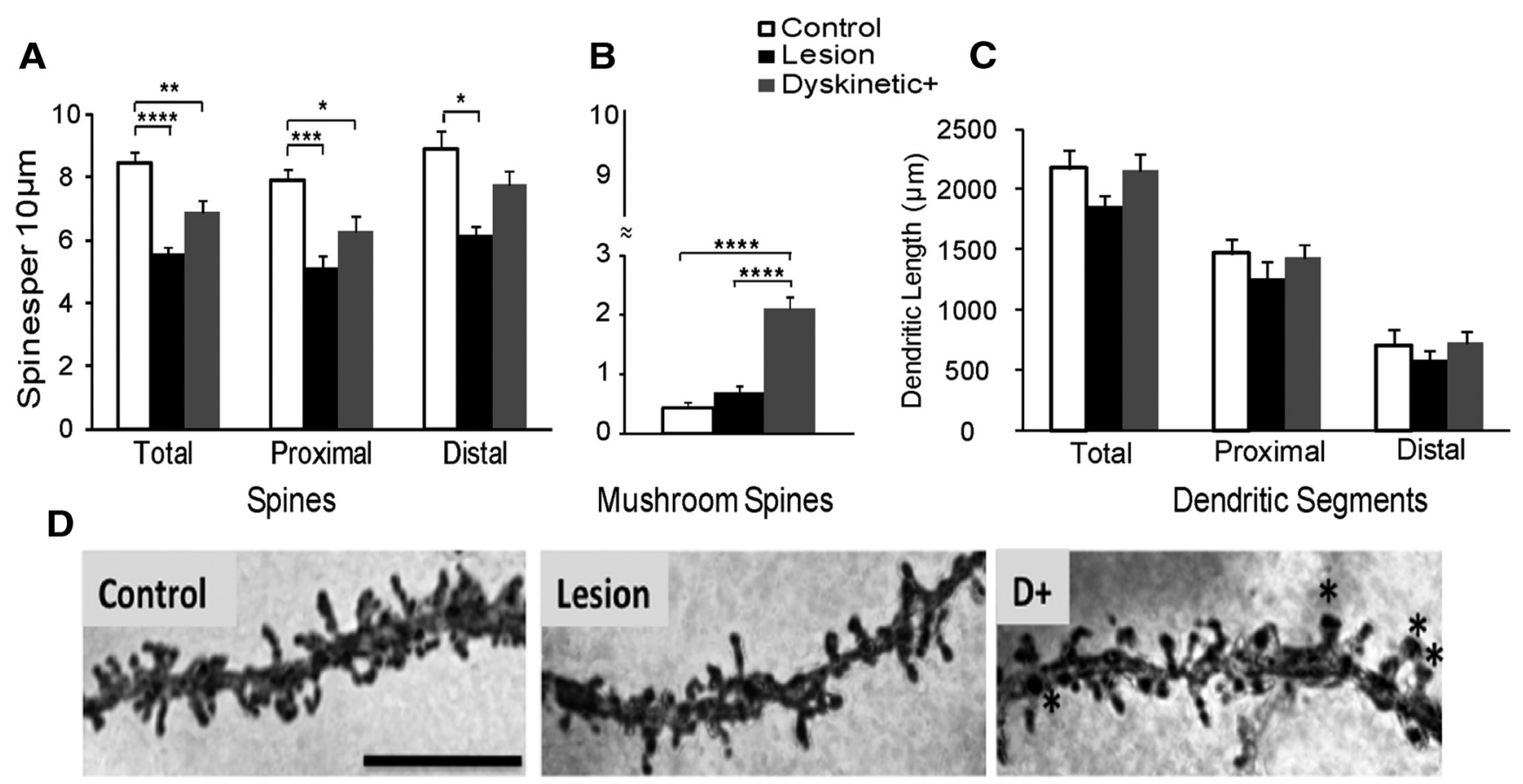

Figure 7. The bar graphs illustrate differences between groups in spine density. $\boldsymbol{A}$, Total density (spines/10 $\mu \mathrm{m})$ for the lesion $(6-0 \mathrm{HDA})$ and dyskinetic ${ }^{+}(D+)$ groups is significantly reduced compared with controls. Proximal (first three branch orders) spine density for the lesion (6-OHDA) and the dyskinetic ${ }^{+}$groups is significantly reduced compared with controls. However, for distal spine density (branch orders four and above), there was a significant loss of spines for the lesion (6-OHDA) group, but not the dyskinetic ${ }^{+}$group, compared with controls. $\boldsymbol{B}$, The density of mushroom spines is significantly increased for the dyskinetic ${ }^{+}$group compared with the lesion (6-OHDA) and control groups. There is no difference between the lesion (6-OHDA) and control groups in the density of mushroom spines. C, The bar graphs illustrate no difference between groups in the total, proximal, or distal dendritic lengths. $D$, Micrographs showing representative dendritic segments from a Golgi-impregnated striatal MSN from control, lesion, and dyskinetic ${ }^{+}$rats. Asterisks $\left(^{*}\right)$ in the micrograph from the dyskinetic ${ }^{+}$animal mark representative mushroom spines. Scale bar, 10 $\mu \mathrm{m}$. Control, $n=6 ; 6-0 \mathrm{HDA}, n=6$; dyskinetic ${ }^{+}, n=6 .{ }^{*} p<0.05,{ }^{* *} p<0.01,{ }^{* * *} p<0.005,{ }^{* * * *} p<0.001$.

kinetic $^{+}$significantly reduced compared with controls, $p=$ 0.008 ; Fig. $7 \mathrm{~A}$ ). For the proximal segments of the dendrites, there was a significant loss of spines for the parkinsonian rat, regardless of dyskinetic status (one-way ANOVA; $F_{(2,31)}=8.60, p=0.001$ ). However, for the dyskinetic ${ }^{+}$rats, the spine losses were confined to the proximal segments of MSNs compared with controls (dyskinetic $^{+}$significantly reduced compared with controls, $p=$ 0.012; Fig. 7A), but for the parkinsonian rats, both proximal (6OHDA significantly reduced compared with controls, $p=0.002$ ) and distal spines were lost compared with controls (one-way ANOVA; $F_{(2,31)}=4.982, p=0.013 ; 6$-OHDA group significantly reduced compared with controls, $p=0.11$; Fig. $7 A$ ). The distal spine density of dyskinetic ${ }^{+}$rats did not differ significantly from controls (dyskinetic ${ }^{+}$was not significantly different compared with controls, $p>0.05)$ and showed no difference with the parkinsonian (6-OHDA) group [trend for dyskinetic ${ }^{+}$to have an increase in spine density compared with parkinsonian (6OHDA) group, $p=0.1]$. These data suggest a restoration of spines in the distal branch orders for the dyskinetic ${ }^{+}$group only. Finally, the density of mushroom, but not branched or thin, spines (Fig. $6 B, D$ ) was significantly greater for the dyskinetic ${ }^{+}$ rats compared with the parkinsonian group (6-OHDA; $H_{(2)}=$ $21.703, p<0.001$; dyskinetic ${ }^{+}$significantly greater than 6-OHDA group, $p<0.05$ ) and control group (dyskinetic ${ }^{+}$significantly more than controls, $p<0.05)$. Neither the length of dendrites (Fig. 7C) nor their surface areas differed between groups (not illustrated).

The ultrastructural analysis of spines showed that multisynaptic spines were increased in the dyskinetic ${ }^{+}$rats compared with controls and parkinsonian (6-OHDA) rats (Table 3). These differences were significant (one-way ANOVA; main effect of dys-
Table 3. Stereological estimates of spines

\begin{tabular}{llll}
\hline Group & $\begin{array}{l}\text { Total spines } \\
\left(\times 10^{8}\right)\end{array}$ & $\begin{array}{l}\text { Multisynaptic spines } \\
\left(\times 10^{8}\right)\end{array}$ & $\begin{array}{l}\text { Multisynaptic/ } \\
\text { total }\end{array}$ \\
\hline Control (sham/saline) & $205 \pm 17.7$ & $0.35 \pm 0.22$ & $0.17 \%$ \\
6-OHDA & $139 \pm 10.7^{*}$ & $0.81 \pm 0.38$ & $0.58 \%$ \\
Dyskinetic $^{+}$ & $131 \pm 11.5^{* *}$ & $1.18 \pm 0.37$ & $0.9 \%^{*}$ \\
\hline
\end{tabular}

Estimates of the total number of spines and multisynaptic spines derived from ultrastructural samples using the physical disector. Values are given as the mean $\times 10^{8} \pm$ SE. ${ }^{*} p<0.05,{ }^{* *} p<0.01$ compared with the control group.

kinesia status, $\left.F_{(2,15)}=8.969, p=0.004\right)$, suggesting that the restoration of VGluT1 ${ }^{+}$axospinous synapses was accommodated, in part, by multiple excitatory inputs onto individual spines. There was no difference in the number of multisynaptic spines between dyskinetic ${ }^{-}$and parkinsonian L-DOPA-naive (6OHDA) rats $(p>0.05)$. Furthermore, we estimate that the total number of asymmetric (excitatory) synapses in the control striatum (immunohistochemically labeled and unlabeled) is $\sim 21.6$ billion; of these, only 35 million single spines receive more than one contact. The total number of asymmetric (excitatory) synapses in the dyskinetic ${ }^{+}$striatum (immunohistochemically labeled and unlabeled) is $\sim 15$ billion, but, in contrast, 118 million of these single spines receive at least two of these contacts.

\section{Discussion}

Nigrostriatal degeneration in PD induces complex morphologi$\mathrm{cal}$ and functional neuroadaptations in striatal circuitry (Day et al., 2006; Villalba and Smith, 2011), and chronic dopamine replacement therapy with L-DOPA likely superimposes further modifications resulting in LIDs (Schuster et al., 2009; Porras et al., 2012). Our data provide the first evidence for a dramatic 

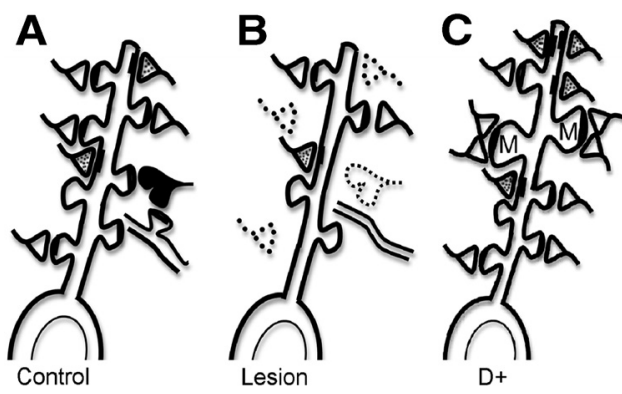

Figure 8. Diagram of VGluT1 ${ }^{+}$synapses contacting an MSN from control (sham/saline; $\boldsymbol{A}$ ), parkinsonian L-DOPA-naive $(6-0$ HDA lesion; $\boldsymbol{B})$, and parkinsonian dyskinetic ${ }^{+}(D+; \boldsymbol{C})$ rats. Asymmetric (excitatory) corticostriatal inputs $\left(\mathrm{VGluT1}^{+}\right.$) contact spines (boutons with white centers) or dendrites (terminals with gray dots). Some synapses are MSBs (black center; i.e., contacting two spines), each on a different neuron, as seen in other parts of the brain (Yankova et al., 2001). $\boldsymbol{B}$, Illustration of the loss of spines and their synapses following the 6-0HDA lesion (dotted lines). $C$, A diagram of the changes the corticostriatal inputs undergo in the $D+$ animals, which includes a full restoration of synapses onto spines, an aberrant increase in multisynaptic (mushroom) spines (M), and an increase in contacts onto dendrites.

rewiring of corticostriatal, but likely not thalamostriatal, synaptic contacts onto morphologically altered MSNs in parkinsonian L-DOPA-treated rats with LIDs (Fig. 8). In this study, rats received a once-daily L-DOPA injection $(12.5 \mathrm{mg} / \mathrm{kg})$, which is comparable to the dose given to late-stage patients with peakdose dyskinesia (Zappia et al., 2005). We selected this dose to induce stable AIMs following the first few injections, rather than a gradual onset of LIDs as in other studies (Putterman et al., 2007). Moreover, once-daily administration causes a pulsatile dopamine efflux in the striatum, which may be a mechanism underlying LIDs (Lindgren et al., 2010).

Our results provide structural evidence that corticostriatal synaptic alterations in the parkinsonian striatum are directly linked to dyskinesias per se, and not chronic L-DOPA administration, in that they were not seen in dyskinetic ${ }^{-}$or control (sham-lesioned) animals administered L-DOPA. As is well known for humans and rodents, nigrostriatal dopamine depletion followed by chronic L-DOPA results in LIDs in many subjects while some subjects remain relatively dyskinesia-free (Cotzias et al., 1969; Grandas et al., 1999; Konradi et al., 2004). The current data corroborate this observation and demonstrate that LIDs do not necessarily correlate with lesion extent (Konradi et al., 2004; Putterman et al., 2007), but, instead, with specific presynaptic and postsynaptic changes (Fig. 8). In particular, when dopamine was transiently replaced with daily L-DOPA, the initial postlesion synaptic loss was followed by a restoration of corticostriatal synapses. This restoration was partial in dyskinetic $^{-}$rats, but increased to control levels in dyskinetic ${ }^{+}$rats. However, synaptogenesis in dyskinetic ${ }^{+}$rats involved the establishment of multiple inputs onto individual spines and the addition of inputs onto dendrites (Fig. 8). Our evidence also demonstrates that in dyskinetic ${ }^{+}$rats, the postsynaptic targets (MSNs) adapted structurally to these synaptic inputs by increasing distal, but not proximal, spines and the number of mushroom spines that presumably hosted the multisynaptic excitatory inputs. These data also show that there is a loss of MSBs across all parkinsonian conditions, regardless of dyskinesia status. The loss of MSBs, which occurs in aged mammals, leads to changes in plasticity (i.e., loss of LTP) and impairments in working memory-dependent tasks (Morrison and Baxter, 2012). A dopaminergic lesion also impairs motor memory and affects LTP and LTD (Ghiglieri et al., 2012). Interestingly, L-DOPA treatment can reinstate LTP (Picconi et al., 2003), but MSBs do not recover in L-DOPA-treated parkinsonian animals, regardless of their dyskinetic state. Yet new synapses do form, particularly from the corticostriatal pathway. These findings suggest that the enduring motor dysfunctions and aberrant LTP seen in LIDs are associated with newly sprouted, long-range connections that form atypical, multiple asymmetric contacts with spines (presumably, mushroom spines), rather than through the remodeling of existing contacts as MSBs.

Dendritic spines are the primary site for excitatory synapses, and, as such, aberrant changes in spine morphology would be expected to lead to pathological changes through alterations in synaptic connections and their strength (Bae et al., 2012; Kuwajima et al., 2012; Murakoshi and Yasuda, 2012). Plasticity of spines is associated with changes in shape and size. As normal spines mature, they receive a connection with just a single glutamatergic presynaptic bouton. However, synaptic input, like spine size and shape, is highly dynamic and linked to morphological spine changes (Okamoto et al., 2004; Bosch and Hayashi, 2012; Murakoshi and Yasuda, 2012). For example, the elevation of calcium within the spine associated with induction of LTP, also increases actin polymerization and results in spine head enlargement and expansion of the active zone of the typical single synapse (Okamoto et al., 2004; Bosch and Hayashi, 2012; Murakoshi and Yasuda, 2012). Thus, in our study, an increase in spine head size expands the active zone area through multiple inputs rather than through expansion of a single active zone.

The relationship between mushroom and multisynaptic spines is clear in the hippocampus (Popov et al., 2007; Popov and Stewart, 2009), but, to our knowledge, this is the first report of multisynaptic spines in the basal ganglia. We found that $<0.2 \%$ of spines in the control striatum have more than one synapse, but these numbers increase dramatically in the dyskinetic striatum. The difference translates to a fivefold increase in multisynaptic spines. In other pathological conditions, for example, Alzheimer's disease or epilepsy, up to nine contacts can be found on a spine (Kuwajima et al., 2012). It is certainly possible that spines in the dyskinetic striatum have even more than two excitatory contacts, since we analyzed only four ultrathin sections in our stereological analyses. Investigations using serial section reconstructions (Yankova et al., 2001; Popov and Stewart, 2009) should be part of a larger effort to understand these pathological changes.

It is important to consider the relationship of the significant increase in the number of mushroom spines that we found with recent data linking an increase in the membrane-associated guanylate kinase postsynaptic density-95 (PSD-95) protein and D1 receptors to LIDs (Nash et al., 2005; Porras et al., 2012). Mushroom spines have larger postsynaptic densities than thin or stubby spines. The postsynaptic membrane is a highly organized structure with an extensive protein network. Inserted in the postsynaptic density are glutamatergic receptors including AMPA and NMDA receptors $(\mathrm{Xu}, 2011)$. An additional key element of the postsynaptic membrane is PSD-95, which is a major scaffolding protein involved in the trafficking and stabilization of the dopamine D1 and glutamatergic receptors, especially AMPA receptors (Bredt and Nicoll, 2003; Porras et al., 2012). LIDs in monkeys resulted in more than a twofold increase in PSD-95 compared with that seen in the parkinsonian striatum without L-DOPA (Porras et al., 2012). Importantly, lowering PSD-95 levels or blocking the interaction of PSD-95 with D1 receptors significantly reduced dyskinesia severity (Porras et al., 2012). This increase in PSD-95 is in agreement with our observation of a 
more than twofold increase in the numbers of mushroom spines in the dyskinetic striatum. Furthermore, studies have shown that overexpression of PSD-95 augments the insertion of AMPA receptors and enhances AMPA receptor-mediated synaptic responses (Yudowski et al., 2013). With new calcium-permeable AMPA receptors inserted into the postsynaptic membrane of mushroom spines and their multiple synaptic surfaces in the dyskinetic striatum, LTP could be enhanced (Stein et al., 2003; Yudowski et al., 2013). Thus, excess production of LTP, noted for the dyskinetic striatum (Picconi et al., 2003; Belujon et al., 2010), may result from an increase in excitatory drive at single spines, which have potentially added new calcium-permeable AMPA receptors, and have been associated with the development and maintenance of LIDs (Kobylecki et al., 2010; Yudowski et al., 2013).

Although our study did not address the issue of whether one class of striatal projection neurons preferentially add synapses from the cortex, other studies give insight into this conundrum. First, the loss of spines and their corticostriatal connections occurs specifically in the indirect pathway neurons following dopamine depletion, which is attributed to elevations in dendritic excitability (Day et al., 2006; Shen et al., 2008; Belujon et al., 2010; Peterson et al., 2012). Indeed, the increase in excitability seems to be caused by the loss of inhibitory signaling at the dopamine D2 receptor (Peterson et al., 2012). Following chronic L-DOPA treatment, the striata of dyskinetic ${ }^{+}$rats lose the ability to establish a form of homeostatic plasticity at glutamatergic synapses, termed "depotentiation," in vitro (Picconi et al., 2003, 2012). When MSNs responsible for this loss are examined in vivo, corticostriatal transmission onto indirect pathway neurons becomes abnormally potentiated in both dyskinetic ${ }^{+}$and dyskinetic ${ }^{-}$rats, but LTP at indirect pathway neurons in the dyskinetic ${ }^{+}$group is characterized as unstable and differs significantly from that in the dyskinetic $^{-}$rats (Belujon et al., 2010). Direct pathway neurons, however, retain a form of LTD comparable to that seen in untreated parkinsonian rats (Belujon et al., 2010). These data therefore suggest that changes in indirect pathway neurons might be an important functional and, perhaps, structural feature of the dyskinetic ${ }^{+}$striatum.

\section{Conclusions}

It appears that LIDs are the result of complex cellular maladaptations when L-DOPA interacts with the already vulnerable striatal circuitry in the dopamine-depleted state (Cenci and Konradi, 2010; Ghiglieri et al., 2012). To our knowledge, this is the first direct evidence demonstrating that specific presynaptic and postsynaptic changes underlie the debilitating dyskinetic symptoms. In particular, it seems likely that an imbalance between corticostriatal and thalamostriatal pathways and aberrant increases in glutamatergic activity at enlarged spines contributes to the pathophysiology. The current study provides compelling evidence that a rewiring of corticostriatal synapses is linked to dyskinetic behaviors. While some aspects of the thalamostriatal system may play a role, the current study cannot confirm its involvement and suggests it plays a lesser role in this behavioral paradigm.

\section{References}

Ahmed I, Bose SK, Pavese N, Ramlackhansingh A, Turkheimer F, Hotton G, Hammers A, Brooks DJ (2011) Glutamate NMDA receptor dysregulation in Parkinson's disease with dyskinesias. Brain 134:979-986. CrossRef Medline

Aubert I, Guigoni C, Håkansson K, Li Q, Dovero S, Barthe N, Bioulac BH, Gross CE, Fisone G, Bloch B, Bezard E (2005) Increased D1 dopamine receptor signaling in levodopa-induced dyskinesia. Ann Neurol 57:17-26. CrossRef Medline

Bae J, Sung BH, Cho IH, Kim SM, Song WK (2012) NESH regulates dendritic spine morphology and synapse formation. PLoS One 7:e34677. CrossRef Medline

Belujon P, Lodge DJ, Grace AA (2010) Aberrant striatal plasticity is specifically associated with dyskinesia following levodopa treatment. Mov Disord 25:1568-1576. CrossRef Medline

Bosch M, Hayashi Y (2012) Structural plasticity of dendritic spines. Curr Opin Neurobiol 22:383-388. CrossRef Medline

Bothwell S, Meredith GE, Phillips J, Staunton H, Doherty C, Grigorenko E, Glazier S, Deadwyler SA, O’Donovan CA, Farrell M (2001) Neural hypertrophy in the neocortex of patients with temporal lobe epilepsy. J Neurosci 21:4789-4800. Medline

Braendgaard H, Gundersen HJ (1986) The impact of recent stereological advances on quantitative studies of the nervous system. J Neurosci Methods 18:39-78. CrossRef Medline

Bredt DS, Nicoll RA (2003) AMPA receptor trafficking at excitatory synapses. Neuron 40:361-379. CrossRef Medline

Calverley RK, Bedi KS, Jones DG (1988) Estimation of the numerical density of synapses in rat neocortex. Comparison of the "dissector" with an "unfolding" method. J Neurosci Methods 23:195-205. CrossRef Medline

Cenci MA, Konradi C (2010) Maladaptive striatal plasticity in L-DOPAinduced dyskinesia. Prog Brain Res 183:209-233. CrossRef Medline

Coggeshall RE (1992) A consideration of neural counting methods. Trends Neurosci 15:9-13. CrossRef Medline

Cotzias GC, Papavasiliou PS, Gellene R (1969) Modification of Parkinsonism-chronic treatment with L-dopa. N Engl J Med 280:337-345. CrossRef Medline

Day M, Wang Z, Ding J, An X, Ingham CA, Shering AF, Wokosin D, Ilijic E, Sun Z, Sampson AR, Mugnaini E, Deutch AY, Sesack SR, Arbuthnott GW, Surmeier DJ (2006) Selective elimination of glutamatergic synapses on striatopallidal neurons in Parkinson disease models. Nat Neurosci 9:251259. CrossRef Medline

De Groot DM (1988) Comparison of methods for the estimation of the thickness of ultrathin tissue sections. J Microsc 151:23-42. CrossRef Medline

de Groot DM, Bierman EP (1986) A critical evaluation of methods for estimating the numerical density of synapses. J Neurosci Methods 18:79-101. Medline

Descarries L, Soghomonian JJ, Garcia S, Doucet G, Bruno JP (1992) Ultrastructural analysis of the serotonin hyperinnervation in adult rat neostriatum following neonatal dopamine denervation with 6-hydroxydopamine. Brain Res 569:1-13. CrossRef Medline

Ding J, Peterson JD, Surmeier DJ (2008) Corticostriatal and thalamostriatal synapses have distinctive properties. J Neurosci 28:6483-6492. CrossRef Medline

Dubé L, Smith AD, Bolam JP (1988) Identification of synaptic terminals of thalamic or cortical origin in contact with distinct medium-size spiny neurons in the rat neostriatum. J Comp Neurol 267:455-471. CrossRef Medline

Figge DA, Rahman I, Dougherty PJ, Rademacher DJ (2012) Retrieval of contexual memories increases activity-regulated cytoskeleton-associated protein in the amygdala and hippocampus. Brain Struct Funct. Advance online publication. Retrieved June 12, 2013. doi:10.1007/s00429-0120453-y. CrossRef Medline

Fujiyama F, Kuramoto E, Okamoto K, Hioki H, Furuta T, Zhou L, Nomura S, Kaneko T (2004) Presynaptic localization of an AMPA-type glutamate receptor in corticostriatal and thalamostriatal axon terminals. Eur J Neurosci 20:3322-3330. CrossRef Medline

Geinisman Y (2000) Structural synaptic modifications associated with hippocampal LTP and behavioral learning. Cereb Cortex 10:952-962. CrossRef Medline

Geinisman Y, deToledo-Morrell L, Morrell F, Persina IS, Rossi M (1992) Structural synaptic plasticity associated with the induction of long-term potentiation is preserved in the dentate gyrus of aged rats. Hippocampus 2:445-456. CrossRef Medline

Geinisman Y, deToledo-Morrell L, Morrell F (1994) Comparison of structural synaptic modifications induced by long-term potentiation in the hippocampal dentate gyrus of young adult and aged rats. Ann N Y Acad Sci 747:452-466. Medline

Geinisman Y, Berry RW, Disterhoft JF, Power JM, Van der Zee EA (2001) 
Associative learning elicits the formation of multiple-synapse boutons. J Neurosci 21:5568-5573. Medline

Ghiglieri V, Bagetta V, Pendolino V, Picconi B, Calabresi P (2012) Corticostriatal plastic changes in experimental L-DOPA-induced dyskinesia. Parkinsons Dis 2012:358176. CrossRef Medline

Grandas F, Galiano ML, Tabernero C (1999) Risk factors for levodopainduced dyskinesias in Parkinson's disease. J Neurol 246:1127-1133. CrossRef Medline

Gras C, Herzog E, Bellenchi GC, Bernard V, Ravassard P, Pohl M, Gasnier B, Giros B, El Mestikawy S (2002) A third vesicular glutamate transporter expressed by cholinergic and serotoninergic neurons. J Neurosci 22:54425451. Medline

Graybiel AM (1995) Building action repertoires: memory and learning functions of the basal ganglia. Curr Opin Neurobiol 5:733-741. CrossRef Medline

Guigoni C, Doudnikoff E, Li Q, Bloch B, Bezard E (2007) Altered D(1) dopamine receptor trafficking in parkinsonian and dyskinetic nonhuman primates. Neurobiol Dis 26:452-463. CrossRef Medline

Gundersen HJ, Bagger P, Bendtsen TF, Evans SM, Korbo L, Marcussen N, Møller A, Nielsen K, Nyengaard JR, Pakkenberg B, Sorensen FB, Vesterby A, West MJ (1988) The new stereological tools: disector, fractionator, nucleator and point sampled intercepts and their use in pathological research and diagnosis. APMIS 96:857-881. CrossRef Medline

Howard V, Reed MG (1998) Unbiased stereology: three-dimensional measurement in microscopy. New York: Springer.

Ingham CA, Hood SH, Arbuthnott GW (1989) Spine density on neostriatal neurones changes with 6-hydroxydopamine lesions and with age. Brain Res 503:334-338. CrossRef Medline

Ingham CA, Hood SH, Taggart P, Arbuthnott GW (1998) Plasticity of synapses in the rat neostriatum after unilateral lesion of the nigrostriatal dopaminergic pathway. J Neurosci 18:4732-4743. Medline

Kobylecki C, Cenci MA, Crossman AR, Ravenscroft P (2010) Calciumpermeable AMPA receptors are involved in the induction and expression of L-DOPA-induced dyskinesia in Parkinson's disease. J Neurochem 114: 499-511. CrossRef Medline

Konradi C, Westin JE, Carta M, Eaton ME, Kuter K, Dekundy A, Lundblad M, Cenci MA (2004) Transcriptome analysis in a rat model of L-DOPAinduced dyskinesia. Neurobiol Dis 17:219-236. CrossRef Medline

Kuwajima M, Spacek J, Harris KM (2012) Beyond counts and shapes: studying pathology of dendritic spines in the context of the surrounding neuropil through serial section electron microscopy. Neuroscience. Advance online publication. Retrieved June 12, 2013. doi:10.1016/j.neuroscience.2012.04.061. CrossRef Medline

Lacey CJ, Boyes J, Gerlach O, Chen L, Magill PJ, Bolam JP (2005) GABA(B) receptors at glutamatergic synapses in the rat striatum. Neuroscience 136: 1083-1095. CrossRef Medline

Lee J, Gomez-Ramirez J, Johnston TH, Visanji N, Brotchie JM (2008) Receptor-activity modifying protein 1 expression is increased in the striatum following repeated L-DOPA administration in a 6-hydroxydopamine lesioned rat model of Parkinson's disease. Synapse 62:310-313. CrossRef Medline

Levine ND, Rademacher DJ, Collier TJ, O'Malley JA, Kells AP, San Sebastian W, Bankiewicz KS, Steece-Collier K (2013) Advances in thin tissue Golgi-Cox impregnation: fast, reliable methods for multi-assay analyses in rodent and non-human primate brain. J Neurosci Methods 213:214227. CrossRef Medline

Lindgren HS, Andersson DR, Lagerkvist S, Nissbrandt H, Cenci MA (2010) L-DOPA-induced dopamine efflux in the striatum and the substantia nigra in a rat model of Parkinson's disease: temporal and quantitative relationship to the expression of dyskinesia. J Neurochem 112:1465-1476. CrossRef Medline

Mayhew TM (1996) How to count synapses unbiasedly and efficiently at the ultrastructural level: proposal for a standard sampling and counting protocol. J Neurocytol 25:793-804. CrossRef Medline

Meredith GE, DeSouza IA, Hyde TM, Tipper G, Wong ML, Egan MF (2000) Persistent alterations in dendrites, spines and dynorphinergic synapses in the nucleus accumbens' shell of rats with neuroleptic-induced dyskinesias. J Neurosci 20:7798-7806. Medline

Morrison JH, Baxter MG (2012) The ageing cortical synapse: hallmarks and implications for cognitive decline. Nat Rev Neurosci 13:240-250. CrossRef Medline

Morshedi MM, Rademacher DJ, Meredith GE (2009) Increased synapses in the medial prefrontal cortex are associated with repeated amphetamine administration. Synapse 63:126-135. CrossRef Medline

Moss J, Bolam JP (2008) A dopaminergic axon lattice in the striatum and its relationship with cortical and thalamic terminals. J Neurosci 28:1122111230. CrossRef Medline

Mouton PR, Gokhale AM, Ward NL, West MJ (2002) Stereological length estimation using spherical probes. J Microsc 206:54-64. CrossRef Medline

Murakoshi H, Yasuda R (2012) Postsynaptic signaling during plasticity of dendritic spines. Trends Neurosci 35:135-143. CrossRef Medline

Nash JE, Johnston TH, Collingridge GL, Garner CC, Brotchie JM (2005) Subcellular redistribution of the synapse-associated proteins PSD-95 and SAP97 in animal models of Parkinson's disease and L-DOPA-induced dyskinesia. FASEB J 19:583-585. CrossRef Medline

Okamoto K, Nagai T, Miyawaki A, Hayashi Y (2004) Rapid and persistent modulation of actin dynamics regulates postsynaptic reorganization underlying bidirectional plasticity. Nat Neurosci 7:1104-1112. CrossRef Medline

Paxinos G, Watson C (1998) The rat brain in stereotaxic coordinates. New York: Academic.

Peters A, Palay SL, Webster HD (1991) The fine structure of the nervous system: neurons and their supporting cells, Ed 3. New York: Oxford UP.

Peterson JD, Goldberg JA, Surmeier DJ (2012) Adenosine A2a receptor antagonists attenuate striatal adaptations following dopamine depletion. Neurobiol Dis 45:409-416. CrossRef Medline

Picconi B, Centonze D, Håkansson K, Bernardi G, Greengard P, Fisone G, Cenci MA, Calabresi P (2003) Loss of bidirectional striatal synaptic plasticity in L-DOPA-induced dyskinesia. Nat Neurosci 6:501-506. Medline

Picconi B, Piccoli G, Calabresi P (2012) Synaptic dysfunction in Parkinson's disease. Adv Exp Med Biol 970:553-572. CrossRef Medline

Popov VI, Stewart MG (2009) Complexity of contacts between synaptic boutons and dendritic spines in adult rat hippocampus: threedimensional reconstructions from serial ultrathin sections in vivo. Synapse 63:369-377. CrossRef Medline

Popov VI, Medvedev NI, Patrushev IV, Ignat'ev DA, Morenkov ED, Stewart MG (2007) Reversible reduction in dendritic spines in CA1 of rat and ground squirrel subjected to hypothermia-normothermia in vivo: a three-dimensional electron microscope study. Neuroscience 149: 549-560. CrossRef Medline

Porras G, Berthet A, Dehay B, Li Q, Ladepeche L, Normand E, Dovero S, Martinez A, Doudnikoff E, Martin-Négrier ML, Chuan Q, Bloch B, Choquet D, Boué-Grabot E, Groc L, Bezard E (2012) PSD-95 expression controls 1-DOPA dyskinesia through dopamine D1 receptor trafficking. J Clin Invest 122:3977-3989. CrossRef Medline

Putterman DB, Munhall AC, Kozell LB, Belknap JK, Johnson SW (2007) Evaluation of levodopa dose and magnitude of dopamine depletion as risk factors for levodopa-induced dyskinesia in a rat model of Parkinson's disease. J Pharmacol Exp Ther 323:277-284. CrossRef Medline

Rademacher DJ, Rosenkranz JA, Morshedi MM, Sullivan EM, Meredith GE (2010) Amphetamine-associated contextual learning is accompanied by structural and functional plasticity in the basolateral amygdala. J Neurosci 30:4676-4686. CrossRef Medline

Schallert T (2006) Behavioral tests for preclinical intervention assessment. NeuroRx 3:497-504. CrossRef Medline

Schmitz C, Hof PR (2007) Design-based stereology in brain aging research. In: Brain aging: models, methods, and mechanisms, Chap 4 (Riddle DR, ed). Boca Raton, FL: CRC.

Schuster S, Doudnikoff E, Rylander D, Berthet A, Aubert I, Ittrich C, Bloch B, Cenci MA, Surmeier DJ, Hengerer B, Bezard E (2009) Antagonizing L-type Ca2 + channel reduces development of abnormal involuntary movement in the rat model of L-3,4-dihydroxyphenylalanine-induced dyskinesia. Biol Psychiatry 65:518-526. CrossRef Medline

Shen W, Flajolet M, Greengard P, Surmeier DJ (2008) Dichotomous dopaminergic control of striatal synaptic plasticity. Science 321:848-851. CrossRef Medline

Small JV (1968) Measurement of section thickness. Paper presented at Fourth European Regional Conference on Electron Microscopy, Rome, September.

Soderstrom KE, Meredith G, Freeman TB, McGuire SO, Collier TJ, Sortwell CE, Wu Q, Steece-Collier K (2008) The synaptic impact of the host immune response in a parkinsonian allograft rat model: Influence on graft- 
derived aberrant behaviors. Neurobiol Dis 32:229-242. CrossRef Medline

Soderstrom KE, O'Malley JA, Levine ND, Sortwell CE, Collier TJ, SteeceCollier K (2010) Impact of dendritic spine preservation in medium spiny neurons on dopamine graft efficacy and the expression of dyskinesias in parkinsonian rats. Eur J Neurosci 31:478-490. CrossRef Medline

Soghomonian JJ, Descarries L, Watkins KC (1989) Serotonin innervation in adult rat neostriatum. II. Ultrastructural features: a radioautographic and immunocytochemical study. Brain Res 481:67-86. CrossRef Medline

Steece-Collier K, Collier TJ, Danielson PD, Kurlan R, Yurek DM, Sladek JR Jr (2003) Embryonic mesencephalic grafts increase levodopa-induced forelimb hyperkinesia in parkinsonian rats. Mov Disord 18:1442-1454. CrossRef Medline

Steece-Collier K, Soderstrom KE, Collier TJ, Sortwell CE, Maries-Lad E (2009) Effect of levodopa priming on dopamine neuron transplant efficacy and induction of abnormal involuntary movements in parkinsonian rats. J Comp Neurol 515:15-30. CrossRef Medline

Stein V, House DR, Bredt DS, Nicoll RA (2003) Postsynaptic density-95 mimics and occludes hippocampal long-term potentiation and enhances long-term depression. J Neurosci 23:5503-5506. Medline

Sterio DC (1984) The unbiased estimation of number and sizes of arbitrary particles using the disector. J Microsc 134:127-136. CrossRef Medline

St-Hilaire M, Landry E, Lévesque D, Rouillard C (2005) Denervation and repeated L-DOPA induce complex regulatory changes in neurochemical phenotypes of striatal neurons: implication of a dopamine D1-dependent mechanism. Neurobiol Dis 20:450-460. CrossRef Medline

Villalba RM, Smith Y (2011) Differential structural plasticity of corticostria- tal and thalamostriatal axo-spinous synapses in MPTP-treated Parkinsonian monkeys. J Comp Neurol 519:989-1005. CrossRef Medline

Wouterlood FG, Härtig W, Groenewegen HJ, Voorn P (2012) Density gradients of vesicular glutamate- and GABA transporter-immunoreactive boutons in calbindin- and $\mu$-opioid receptor-defined compartments in the rat striatum. J Comp Neurol 520:2123-2142. CrossRef Medline

Xu W (2011) PSD-95-like membrane associated guanylate kinases (PSDMAGUKs) and synaptic plasticity. Curr Opin Neurobiol 21:306-312. CrossRef Medline

Xu ZC, Wilson CJ, Emson PC (1991) Restoration of thalamostriatal projections in rat neostriatal grafts: an electron microscopic analysis. J Comp Neurol 303:22-34. CrossRef Medline

Yahr MD, Duvoisin RC, Schear MJ, Barrett RE, Hoehn MM (1969) Treatment of parkinsonism with levodopa. Arch Neurol 21:343-354. CrossRef Medline

Yankova M, Hart SA, Woolley CS (2001) Estrogen increases synaptic connectivity between single presynaptic inputs and multiple postsynaptic CA1 pyramidal cells: a serial electron-microscopic study. Proc Natl Acad Sci U S A 98:3525-3530. CrossRef Medline

Yudowski GA, Olsen O, Adesnik H, Marek KW, Bredt DS (2013) Acute inactivation of PSD-95 destabilizes AMPA receptors at hippocampal synapses. PLoS One 8:e53965. CrossRef Medline

Zappia M, Annesi G, Nicoletti G, Arabia G, Annesi F, Messina D, Pugliese P, Spadafora P, Tarantino P, Carrideo S, Civitelli D, De Marco EV, CiròCandiano IC, Gambardella A, Quattrone A (2005) Sex differences in clinical and genetic determinants of levodopa peak-dose dyskinesia in Parkinson's disease: an exploratory study. Arch Neurol 62:601-605. CrossRef Medline 